\title{
Toxicology of chemically modified graphene-based materials for medical application
}

\author{
Toktam Nezakati $\cdot$ Brian G. Cousins • \\ Alexander M. Seifalian
}

Received: 26 August 2014 / Accepted: 3 September 2014 / Published online: 19 September 2014

(C) The Author(s) 2014. This article is published with open access at Springerlink.com

biotechnology, and nanomedicine to aid in the diagnosis and treatment of a variety of debilitating diseases.

Keywords Biocompatibility · Graphene - Graphene oxide $\cdot$ In vitro $\cdot$ In vivo $\cdot$ Toxicity

$\begin{array}{ll}\text { Abbreviations } \\ { }^{\circ} \mathrm{C} & \text { Centigrade } \\ 0 \mathrm{D} & \text { Zero dimensional } \\ 1 \mathrm{D} & \text { One-dimensional } \\ 2 \mathrm{D} & \text { Two-dimensional } \\ \text { 3D } & \text { Three-dimensional } \\ 4 \mathrm{~T} 1 & \text { Murine breast tumor mice } \\ \mathrm{A} 549 & \text { Human lung adenocarcinoma epithelial cell } \\ & \text { line } \\ \mathrm{Au} & \text { Aurum, gold } \\ \mathrm{CD} 105 & \text { Endoglin } \\ \mathrm{Ce} 6 & \text { Chlorin e6 } \\ \mathrm{CGN} & \text { Thermo-sensitive nanogel } \\ \mathrm{CNT} & \text { Carbon nanotube } \\ \mathrm{CrGO} & \text { Chemically reduced GO } \\ \mathrm{Cu} & \text { Copper } \\ \mathrm{CVD} & \text { Chemical vapor deposition } \\ \mathrm{Da} & \text { Dalton } \\ \mathrm{DNA} & \text { Deoxyribonucleic acid } \\ \mathrm{DOX} & \text { Doxorubicin } \\ \text { FA } & \text { Folic acid } \\ \text { FACS } & \text { Fluorescence-activated cell sorting } \\ \text { FDA } & \text { Food and drug administration } \\ \text { Fe }{ }_{3} \mathrm{O}_{4} & \text { Ferric oxide } \\ \text { FGO } & \text { Fibrin-coated GO } \\ \mathrm{FMA} & \text { Fluorescein } O \text {-methacrylate } \\ \mathrm{g} & \text { Gram } \\ \mathrm{G} & \text { Graphene } \\ \mathrm{Ga} & \text { Gallium } \\ & \end{array}$




\begin{tabular}{|c|c|c|c|}
\hline GAP-43 & Growth-associated protein 43 & PGE-DSPE & 1,2-Distearoyl-sn-glycero- \\
\hline Gel & Gelatin & & 3-phosphoethanolamine- \\
\hline Gelatin-GNS & Gelatin graphene nanosheets & & $N$-[amino(polyethylene glycol)] \\
\hline $\mathrm{GO}$ & Graphene oxide & MCF7 & Michigan cancer foundation-7 breast \\
\hline GOT & Graphene oxide $/ \mathrm{TiO}_{2}$ & & cancer cell \\
\hline $\mathrm{HB}$ & Hypocrellin B & $\mathrm{pH}$ & Power of hydrogen \\
\hline HeLa & Henrietta Lacks cell & PLA & Polylactic acid \\
\hline HepG2 & Human hepatoma & PMEF & Primary mouse embryonic fibroblast \\
\hline HLF & Human lung fibroblast & PTT & Photo-thermal therapy \\
\hline hMSC & Human mesenchymal stem cells & PVP & Polyvinylpyrrolidone \\
\hline \multirow[t]{2}{*}{ HPPH } & 2-(1-Hexyloxyethyl)-2-devinyl & $\mathrm{RBC}$ & Red blood cell \\
\hline & pyropheophorbide-alpha & rGO & Reduced graphene oxide \\
\hline IONP & Iron oxide nanoparticles & rGONP & Reduced graphene oxide nanoplatelet \\
\hline iPSC & Induced pluripotent stem cell & RNA & Ribonucleic acid \\
\hline \multirow[t]{2}{*}{ iTRAQ } & Isobaric tags used for relative and absolute & $\mathrm{SiC}$ & Silicon carbide \\
\hline & quantification & SKBR3 & Sloan-Kettering breast cancer cell \\
\hline $\mathrm{K}$ & Kelvin & SWNT & Single-wall carbon nanotube \\
\hline $\mathrm{KClO}_{3}$ & Potassium chlorate & $\mathrm{T}$ & Troponin \\
\hline $\mathrm{Kg}$ & Kilogram & TCP & Tissue culture polystyrene \\
\hline LA & Lactobionic acid & $\mathrm{Ti}$ & Titanium \\
\hline LC3 & Light chain 3 & $\mathrm{TiO}_{2}$ & Titanium dioxide \\
\hline \multirow[t]{2}{*}{ LC-MS/MS } & Liquid chromatography-tandem mass & $\mathrm{TPa}$ & Tera pascal \\
\hline & spectrometry & TRC105 & Human chimeric monoclonal antibody to \\
\hline LP & Linear polyethylenimine & & CD105 \\
\hline $\mathrm{m}$ & Meter & $\mathrm{U} 251$ & Human glioma cell \\
\hline \multirow[t]{2}{*}{ MCF7 } & Michigan cancer foundation-7 breast can- & UCNP & Up-conversion nanoparticles \\
\hline & cer cell & UK & United Kingdom \\
\hline MFG & Multi-functional graphene & US & United States \\
\hline $\mathrm{mg}$ & Milligram & $\mathrm{W}$ & Watt \\
\hline MG-63 & Osteoblast-like cell line & $\mu g$ & Microgram \\
\hline
\end{tabular}

MHC Major histocompatibility complex

MHRA Medicines and healthcare products regulatory agency

$\mathrm{mL} \quad$ Milliliter

MR Magnetic resonance

M-rGO Microbially reduced graphene oxide

MTT Methyl thiazolyl tetrazolium

MTX Methotrexate

MWNT Multi-wall carbon nanotube

MyoD Myogenin

NGR Nitrogen ion-implanted graphene

$\mathrm{Ni} \quad$ Nickel

NIH-3T3 National institute of health 3T3 mouse

fibroblast cell

NIR Near-infrared

NOTA 1,4,7-Triazacyclononane-1,4,7-triacetic acid

NSC Neural stem cell

O-GNR Oxidized graphene nanoribbons

PDT Photodynamic thermal therapy

PEG Polyethylene glycol

PEI Polyethylenimine

PET Positron emission tomography

\section{Introduction}

There is only a relatively small contribution regarding the safety profile and toxicology data in the literature on graphene-based materials outlining their interactions in biological systems with cells and tissues. Over the last 5 years alone, over 424 publications and cited articles relate to graphene toxicology, which has increased to 1,015 publication by 2009 to approximately 3,753 in 2013, whereby the vast majority focus on the physical and material properties of graphene and is a subject of intensive research (Liao et al. 2011; $\mathrm{Hu}$ et al. 2011). The physicochemical interaction of graphene, and their use in biological systems, is perhaps one of the newest and fastest growth areas of carbon-based nanomaterials research. Much study in this area is inspired by the myriad of possibilities of many useful biomedical applications relating to their unique properties and to address healthcare concerns relating to nanotoxicology (Liu et al. 2008; Chang et al. 2011a). There has been an intensive focus over the last 10 years in the application of carbon-based nanomaterials such as charcoal, graphite, 
Fig. 1 Graphene is a 2D building material for allotropes of carbon nanomaterials. It can be wrapped up into $0 \mathrm{D}$ buckyball, rolled into a $1 \mathrm{D}$ nanotube, or and Novoselov 2007) stacked into 3D graphite (Geim
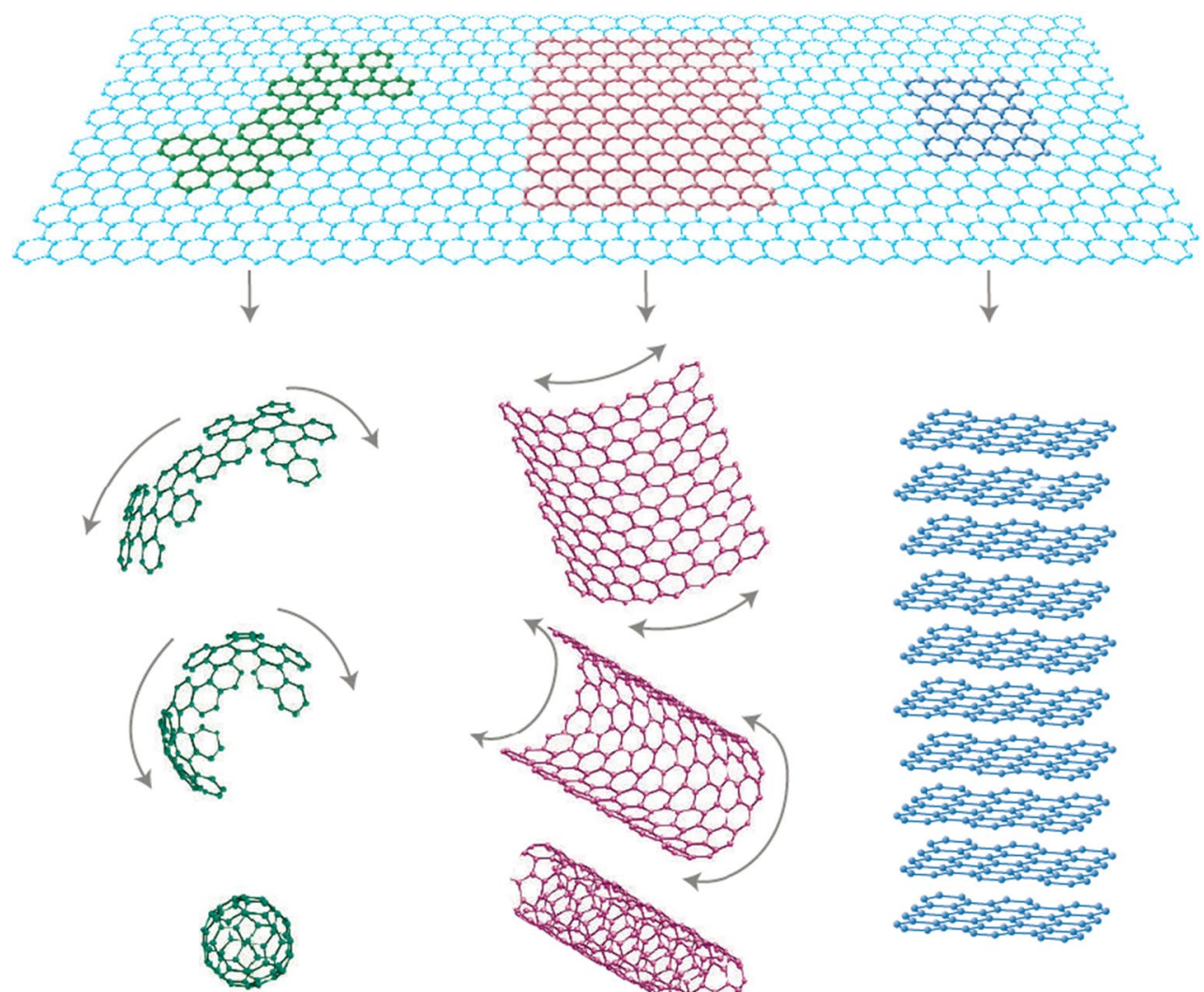

fullerene, single-wall carbon nanotubes (SWCNTs), multiwall carbon nanotubes (MWCNTs), and graphene. This is due to the exploitation of their unique properties, such as enhanced electrical, thermal, mechanical, and optical properties, which provides a range of different application areas from advanced electronics and imaging to biomaterials and biological sensors for diagnostic use. However, a major concern, involving graphene-based materials, is that there is a limited knowledge relating to their environmental toxicity and biological safety profile. The UK government body, the Medicines and Healthcare Products Regulatory Agency (MHRA), and the US Food and Drug Administration (FDA) are now reviewing all forms of graphene and functionalized graphene oxide (GO) due to their poor solubility, high agglomeration, long-term retention, and relatively long circulation time in the blood (Begum et al. 2011). Extensive testing is now deemed essential for graphene-based materials both for now and in the near future to assess their biological safety profile, which is dependent upon different physicochemical factors relating to their surface chemistry, charge, size, shape, and relative concentration. Yet still there are many unresolved issues, which remain and need to be clarified before their eventual use for healthcare applications can be fully realized. The biocompatibility and toxicity behavior of graphene-based material in biological systems gives rise to many important
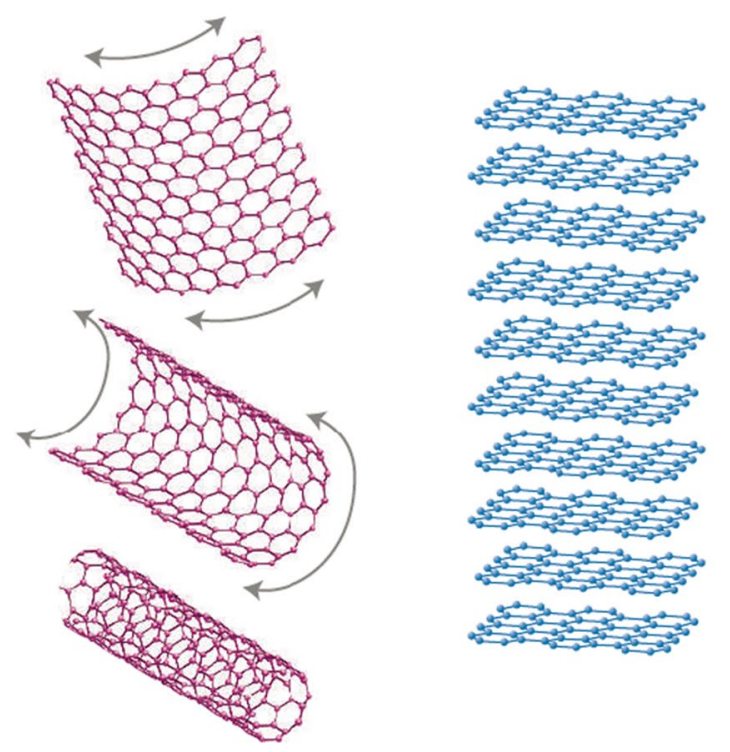

fundamental issues that require significant attention, and numerous studies are now needed to fill the knowledge gap before being considered as truly 'safe' for human use.

\section{Graphene structure and related properties}

Graphene is composed of single-carbon atoms forming a sheet of close-packed hexagonal array of $\mathrm{SP}^{2}$ hybridized bonds and can be considered as large aromatic molecule. As such, they have attracted a significant amount of attention in recent times, especially in various areas of biophysics and biotechnological applications (Mao et al. 2013b). The two-dimensional, graphene flat sheets can be formed into different geometries, which can be wrapped into spherical structures (0D fullerenes, $\mathrm{C}_{20}, \mathrm{C}_{40}, \mathrm{C}_{60}$ ), rolled into 1D structures as a single-sheet CNTs, or stacked into 3D-layered structures such as graphite (Fig. 1) (Geim and Novoselov 2007). This is due to their exceptional material properties giving rise to unique chemical, electrical and thermal conductivity $\left(\sim 5,000 \mathrm{Wm}^{-1} \mathrm{~K}^{-1}\right)$, mechanical, optical transmittance $(\sim 97.7 \%)$, structural, and thermal behavior, and has shown great promise for many application areas relating to electronics, semiconductor fabrication, and the biomedical industry (Zhu et al. 2010; Compton and Nguyen 2010; Rao et al. 2009). Graphene has a number 


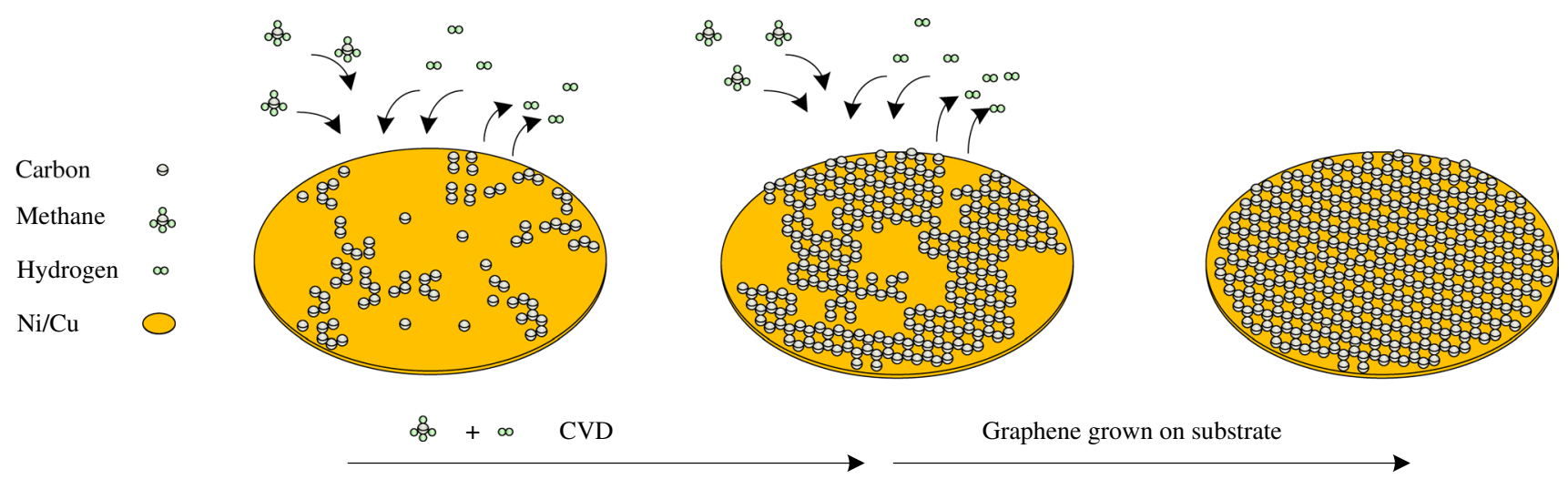

Fig. 2 Bottom-up fabrication, by chemical vapor deposition (CVD)

of fascinating physical characteristics such as the highest surface area $\left(\sim 2,600 \mathrm{~m}^{2} / \mathrm{g}\right)$ (Li et al. 2008) and a relatively high Young's modulus ( $<1 \mathrm{TPa}$ ) among all known materials (Lee et al. 2008), and capable of mass production through a number of chemical manufacturing and material processing such as non-covalent and covalent surface modification using surfactants, and biofunctionalization to exploit their unique properties (Shao et al. 2010). Moreover, graphene consists of a layer of $\pi$-conjugated systems usually involving six-atom rings. This planar structure offers an excellent capability to interact with a variety of aromatic compounds through $\pi-\pi$ stacking interactions in the manufacture of nanocomposite materials and in the immobilisation of biomolecules such as peptides, antibodies, and other therapeutic agents (Boehm 1986; Wintterlin and Bocquet 2009; Van Bommel et al. 1975; Lu et al. 1999a, b; Novoselov et al. 2004). Therefore, graphene has generated great interest in the field of nanomedicine and has been successfully applied in biosensing applications via targeted and selective delivery (Shao et al. 2010; Akhavan et al. 2012b), bioimaging, cell culture, cancer detection, gene delivery (Boehm 1986; Wintterlin and Bocquet 2009; Van Bommel et al. 1975; Lu et al. 1999a, b; Novoselov et al. 2004; Berger et al. 2004; Li et al. 2009; Stankovich et al. 2006), disease diagnosis (Mohanty and Berry 2008), anti-bacterial compounds (Akhavan and Ghaderi 2009, 2010, 2012; Hu et al. 2010; Ma et al. 2011; Akhavan et al. 2011), anti-viral materials (Akhavan et al. 2012c), photo-thermal therapy (Yang et al. 2012b; Zhang et al. 2011a; Akhavan et al. 2012a), drug delivery (Sun et al. 2008; Liu et al. 2008, Li et al. 2011; Zhang et al. 2010a), and tissue engineering applications (Park et al. 2010; Agarwal et al. 2010; Heo et al. 2011). Therefore, all of their interesting material properties propel graphene from the research laboratory to real-life biological and clinical applications and show great potential for further exploitation and use within the biomedical industry ready for clinical use.

\section{Graphene preparation and manufacture}

The preparation of graphene can be divided in two main categories: (1) bottom-up and (2) top-down fabrication techniques. Bottom-up fabrication is achieved using several methods to prepare high-quality graphene such as chemical vapor deposition (CVD). These methods produce highly crystalline graphene, but are not suitable for mass production (Graphene et al. 2010; Kim et al. 2011). For example, CVD is a method which opens up scalable and transparent high-quality graphene in ultra-high vacuum (UHV) conditions $\left(10^{-4}-10^{-6} \mathrm{pa}\right)$ at high temperature $\left(1,000{ }^{\circ} \mathrm{C}\right)$ using gasses such as methane $-\mathrm{CH}_{4}$ (g) as a carbon source as highlighted in Fig. 2. The CVD process revolves around a piece of copper $(\mathrm{Cu})$ foil on silicon substrate, which is used as catalyst, which graphene is able to grow as a fibrous 'mat'like material. At very high temperatures in an extreme clean, UHV chamber (or environment), carbon from $\mathrm{CH}_{4}$ forms graphene on top of the $\mathrm{Cu}$ or nickel (Ni) foil (Fig. 2). Current methods are derived from chemical modification, and functionalized GO and reduced graphene oxide (rGO) within the top-down category are achieved through chemical exfoliation (Novoselov et al. 2012; Dreyer et al. 2010). Chemical exfoliation, described by Schafhaeutl, in the 1940s is a method, which uses a wide range of chemicals such as acid or alkali metals (e.g., potassium), fluoride salts of various types, and transition metals (e.g., iron, nickel), to obtain GO (Dreyer et al. 2010). Nineteen years after Schafhaeutl described this method, British chemist, Broid, used a chemical exfoliation process to manufacture GO. This method can characterize the molecular weight of graphite by using acids (e.g., sulfuric and nitric), as well as oxidants, such as potassium chlorate $\left(\mathrm{KClO}_{3}\right)$. Further exfoliation with ultrasonication, thermal or energetic conditions help to oxidize stacked layers of hexagonally arranged carbon atoms that are bonded together with an inter-planar force to obtain graphene layers. The use of this method led 

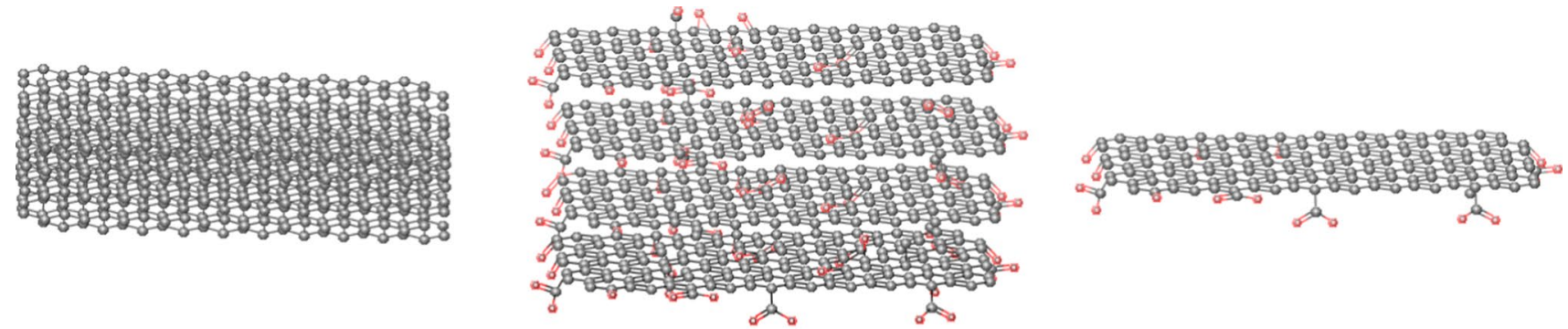

Graphite

Oxidation (H2SO4, $\mathrm{KMnO} 4)$

Graphene Oxide

Reduction (Hydrazine)

\section{Graphene}

Fig. 3 Top-down fabrication, solution based on Hummer's method using ultrasonication

to the formation and production of single-layer-reduced GO (Dreyer et al. 2010). Top-down fabrication involves a chemical reduction based on Hummer's method (Hummers and Offeman 1958), and chemical oxidation of graphite followed by ultrasonication is highlighted in Fig. 3.

\section{Use of graphene in biomedical applications}

Owing to graphene's low level of toxicity, the lethal dose (LD50) of graphite has been reported as $2 \mathrm{~g} / \mathrm{per}$ kilo (Sebastian 2012); the following sections outline some of the most promising application areas, use of graphene for enhanced imaging, diagnostics and therapeutic applications in nanomedicine, and their use as novel materials for improved medical devices via improvements in their mechanical properties, and photosensitivity has received considerable attention, along with their health and safety and regulatory concerns (Yang et al. 2010, 2011a, b).

\section{Drug delivery applications}

The treatment of cancer represents a global challenge to public health care and is a leading cause of over 7 million deaths worldwide annually (Wood 2013; Boyle and Levin 2008). One significant and area of great importance in the treatment of cancer is the application of chemotherapy. This approach has proved successful in the treatment of various cancers, such as acute promyelocytic leukemia (Jing 2001; Chen et al. 1997), lung (Carney et al. 1983; Umezawa et al. 1966; Kouranos et al. 2011), head and neck cancers. However, the lack of therapeutic efficacy confines such clinical applications due to drug resistivity, low efficiency of cellular uptake, and high proportion of side effects, such as liver and kidney damage (Calvert et al. 1989; Kintzel and Dorrt 1995), hair loss (Jaracz et al. 2005; Narang and Varia 2011), nausea and cardiac toxicity (Chithrani et al. 2009; Geiger et al. 2010; Voortman and Giaccone 2006).
Therefore, novel materials with minimal side effects, low toxicity, and high efficiency of targeted drug delivery enhance the bioavailability for chemotherapy, which is an area of increasing research interest (Abou-jawde et al. 2003; Manuscript 2009). Lung cancer is the primary cause of death for all known cancers worldwide (Deaths 2011; Jemal et al. 2011), and due to the size and distribution, cyto-reductive surgery is rarely a viable treatment option. Chemotherapy based on cytotoxic drugs kills cancer cells, which is the main popular approach for treatment of lung cancer. However, the lack of targeting specificity leads to severe side effects such as hemorrhage (Manuscript and Factors 2008). More effective localized delivery can lead to substantial improvements in curative and therapeutic modes of action not only for chemical-based treatments, but for MRI gene delivery including contrast enhancers and radiation sensitizers. In addition, the precise diagnosis and therapy are difficult in most cases for the limited options available (Shi et al. 2013a). Therefore, enormous endeavor in biomedical research has been dedicated to developing new approaches for early-stage detection, diagnosis, and therapy of cancer, which is now commonly referred to as 'theranostics' (Mura and Couvreur 2012). Driven by an unmet clinical need, highly integrated drug delivery nanocarriers rely for simultaneous imaging and therapy are currently being evaluated (Huang et al. 2012; Melancon et al. 2011; Liang 2011; Jokerst and Gambhir 2011). Graphene and its derivatives, such as GO, reduced GO, and GO nanocomposites, are some of the more well-known examples (Feng and Liu 2011). Externally controlled non-invasive drugs with reliable remote sensing and repeatable 'on' and 'off' molecular switches to control drug release have recently been receiving attention (Thomas et al. 2010). This method consists of drug-releasing technology via an external stimulus to induce carrier responsive and material properties. The external stimulus is usually derived from polarized or infrared (IR) light (Yavuz et al. 2009; Sherlock et al. 2012; Lu et al. 2008), magnetic field strength (Hoare 


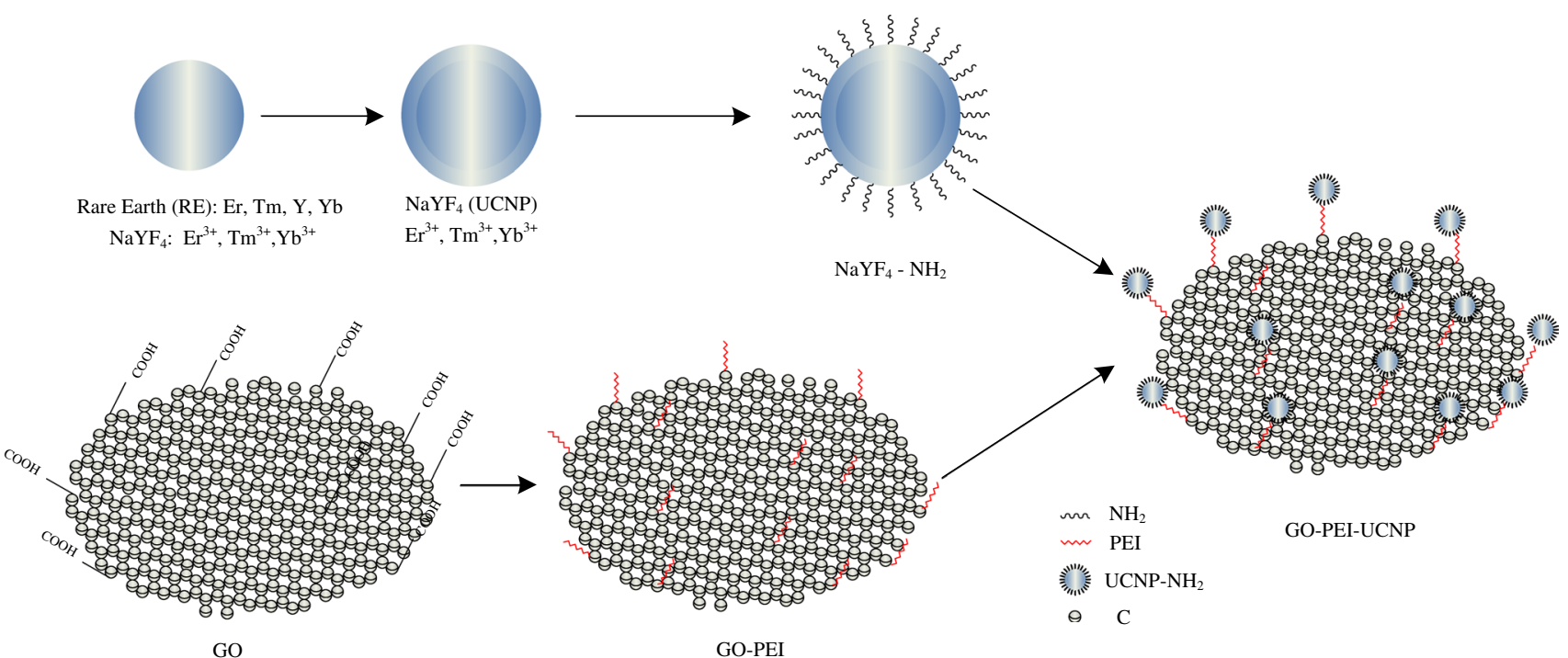

Fig. 4 Schematic diagram of the procedure for GO-PEI-UNCP: Numbers of core-shell structured UCNPs covalently grafted with GO through polyethylenimine for advanced imaging, drug delivery, and photo-thermal therapy

et al. 2009; Thomas et al. 2010), ultrasound (Hu and Zhou 2014), and radio frequency-induced drug delivery (Santini et al. 1999; Grayson et al. 2003).

Photo-thermal therapy (PTT)

Photo-thermal therapy (PTT) converts light or optical energy to heat by absorption of a range of nanomaterial (e.g., silica-coated gold nanoparticles), leading to the thermal ablation resulting in the death of cancer cells. In recent years, PTT as a minimally invasive, controllable, and highly efficient treatment method has drawn widespread attention in the treatment of cancer. A large number of research groups have developed various light-absorbing nanomaterials as PTT agents (Huang et al. 2006; Chen et al. 2007; Yavuz et al. 2009; Wu et al. 2010; Dong et al. 2011; Tian et al. 2011; Cheng et al. 2011, 2012; Yang et al. 2010, 2012b, c; Moon et al. 2009; Liu et al. 2011; Wang et al. 2011, 2012), all with absorbance values in the nearinfrared (NIR) region $(560-760 \mathrm{~nm})$, which is the region ideal for controlling interactions with biological tissues. Despite the great promise of PTT in cancer treatment using nanomaterials, the development of a new generation of PTT agents with enhanced NIR absorption and multiple functions to realize imaging-guided highly effective cancer therapy still merits further effort. Carbon-based nanomaterials, such as CNTs, carbon nanohorns, and graphene, are being extensively studied as potential PTT agents (Moon et al. 2009; Liu et al. 2011; Wang et al. 2011, 2012; Yang et al. 2010, 2012b). Besides inorganic materials, organic nanoparticles, such as polypyrrole and other light-absorbing conductive polymers, have also shown potential in
PTT cancer ablation in a few recent studies (Cheng et al. 2012; Yang et al. 2012c; Chen et al. 2012c; Zha et al. 2013). Nanoparticle-based NIR-PTT provides an encouraging remedy and strategy for efficient tumor ablation with minimum injury to the surrounding tissues. Up-conversion of nanoparticles (UCNPs) is a further approach to PTT. As an example, UNCP, water-dispersible nanocrystals, which is fluorophores and magnetic nanoparticles, whereby ferric oxide $\left(\mathrm{Fe}_{3} \mathrm{O}_{4}\right)$ is reacted with polyethylenimine-modified GO (PEI-GO) acting as a nanocarrier attached to the nanocrystals to yield PEI-GO-nanocrystal (Yan et al. 2013). PEI-GO-UCNP is able to load water-insoluble anticancer drugs, such as doxorubicin (DOX), with a superior loading capacity of $100 \mathrm{wt} \%$, through hydrophobic, $\pi-\pi$ stacking interaction between PEI-GO-UCNP, and an aromatic drug highlighted in Fig. 4. Chemotherapy and PTT when used in combination have been proven to reduce drug resistance, and to be an effective strategy to improve the cancer therapy efficacy (Tang et al. 2010; Tang and Mcgoron 2009; Hauck et al. 2008; Lee et al. 2010). In contrast, undesired damage to normal tissues may be caused by non-specific, untargeted drug delivery and heat supplied to the tumor area. Moreover, recent studies suggest that graphene possesses a higher photo-thermal sensitivity than CNTs, and is more effective in PTT in the treatment of cancer (Markovic et al. 2011; Yang et al. 2010, 2012a; Tian et al. 2011).

Nerve repair and regeneration

There is currently an unmet clinical need for biocompatible and conductive materials used for neurological 
applications, which are crucial in the development of next generation of chronic (long-term) implants used in the peripheral and central nervous system (CNS). Nanoparticles incorporated into polymeric conduits, acting as fillers, such as, graphene, CNTs, and fullerene, can become one possible solution in the production of conducting materials, which are necessary for stimulating cell growth, and delivery of therapeutic agents. Identification of neural stem cell differentiation is an essential stage for the practical application of stem cell technology in regenerative medicine. Cell differentiation and monitoring is incredibly important for the application of neural stem cells (NSCs) in the treatment of neurodegenerative disease such as Alzheimer's (Steindler and Okun 2012), Parkinson's disease (Steindler and Okun 2012; Daadi et al. 2012; Xie et al. 2012), and also, traumatic spinal cord injury (Li et al. 2012; Donnelly et al. 2012). Many conventional tools have been used to detect the differentiation potential of NSCs, as well as to distinguish the undifferentiated NSCs from differentiated neuronal and glial cells (Danova-alt et al. 2012; Ganat et al. 2012; Piao et al. 2012; Buján et al. 2005; Xu et al. 2012).

\section{Risk assessments of graphene-based nanomaterials}

According to the elemental composition of carbon atoms arranged within the graphene layer or as discrete nanoparticles, knowledge of influential factors such as their surface chemistry (energy, charge, and wettability), morphology, geometry and aggregation behavior and solubility will influence the particle distribution within the surrounding environment. Nanoparticles when present in physiological fluids such as plasma or serum redistribute themselves throughout the host tissues and are transported to the liver, lungs, spleen, heart, kidney, and bone marrow due to their material and surface properties, and how they interact as a consequence of proteins that adsorb on to the surface can cause nanoparticle aggregation and cell uptake (Gajewicz et al. 2012). Figure 5 illustrates the toxicology overview on the principal components of graphene, the tests that are required, risk factors, and their eventual characterization, highlighting the need for standardization for testing this class of material. Investigation via in vitro studies has shown that the indirect contact with nanomaterials with mammalian cells causes cytotoxic reactions, such as oxidant release via reactive oxygen species (ROS) and stress followed by cytokine release and inflammation, which is primarily in response to ROS ( Nel 2005; Nel et al. 2006; Oberdörster et al. 2005), cell damage and lipid peroxidation of cellular membranes (Nel et al. 2006; Oberdörster et al. 2005; Panessa-Warren et al. 2006, 2008). Such events are known to cause changes in gene expression, which involve irregular signaling cues influencing cell fate resulting in further inflammation (Cui et al. 2005). The toxicity profile of graphene and GO nanoparticles remains elusive, since their characterization, bulk and chemical composition are very similar at the nanometer length scale. Figure 6 shows the potential distribution of graphene, highlighting the target organs and systems and distribution throughout the human body (Zhao and Liu 2012). A number of previous studies report that pristine graphene or GO without further surface modification causes severe pulmonary distress after inhalation causing excessive inflammation (Duch et al. 2011). Intravenous (i.v.) injection of functionalized graphene into mice is known to accumulate in the lung resulting in pulmonary edema and granuloma formation (Wang et al. 2010; Zhang et al. 2011a, b). Furthermore, surfacefunctionalized graphene with improved hydrophilicity and better stability in the physiological environment appears to be far less toxic (Singh et al. 2012; Yang et al. 2011a, b). In Fig. 6, graphene can easily enter into the lungs via the respiratory system and later distribute themselves in the circulatory system via the blood and lymph fluid (Fig. 6). Further investigation into the distribution of graphene has found that the materials can penetrate into the tissues of the heart, spleen, kidney, bone marrow, and liver. The major risks to health care associated with the manufacture of carbon-based nanomaterials are to the eyes and the lungs, and can cause substantial irritation and inflammation (Kayat et al. 2011).

Exposure assessment of graphene

Due to the ever expanding applications of nanotechnology, human and environmental exposures to graphenebased nanomaterials are likely to increase both now and in the near future (Seabra et al. 2014). It is still not clear how to establish the precise mechanism or precise laboratory-based test for determining the potential toxicity of nanoparticles. In the development of novel nanomaterials, considerable effort is needed to perform as broader risk characterization as possible (Worth 2010). Currently, one of the general market risk assessment methods is exposure methods to determine whether an exposed population and dependent exposures factors like frequency, magnitude, and duration have a cumulative effect. Other methods rely upon hazard assessments like identification and characterization of known hazards. Environmental factors also determine the exposure levels and distribution of the chemicals in the natural environment such as the levels present in the soil, sediment, water, and air, and any analytical measures as to the conversion or deterioration of chemicals, and the media containing the specific agents movement throughout the environment. The specific risk of the materials can be estimated, processed, and individualized within any given systems, while the hazard assessments will qualitatively 

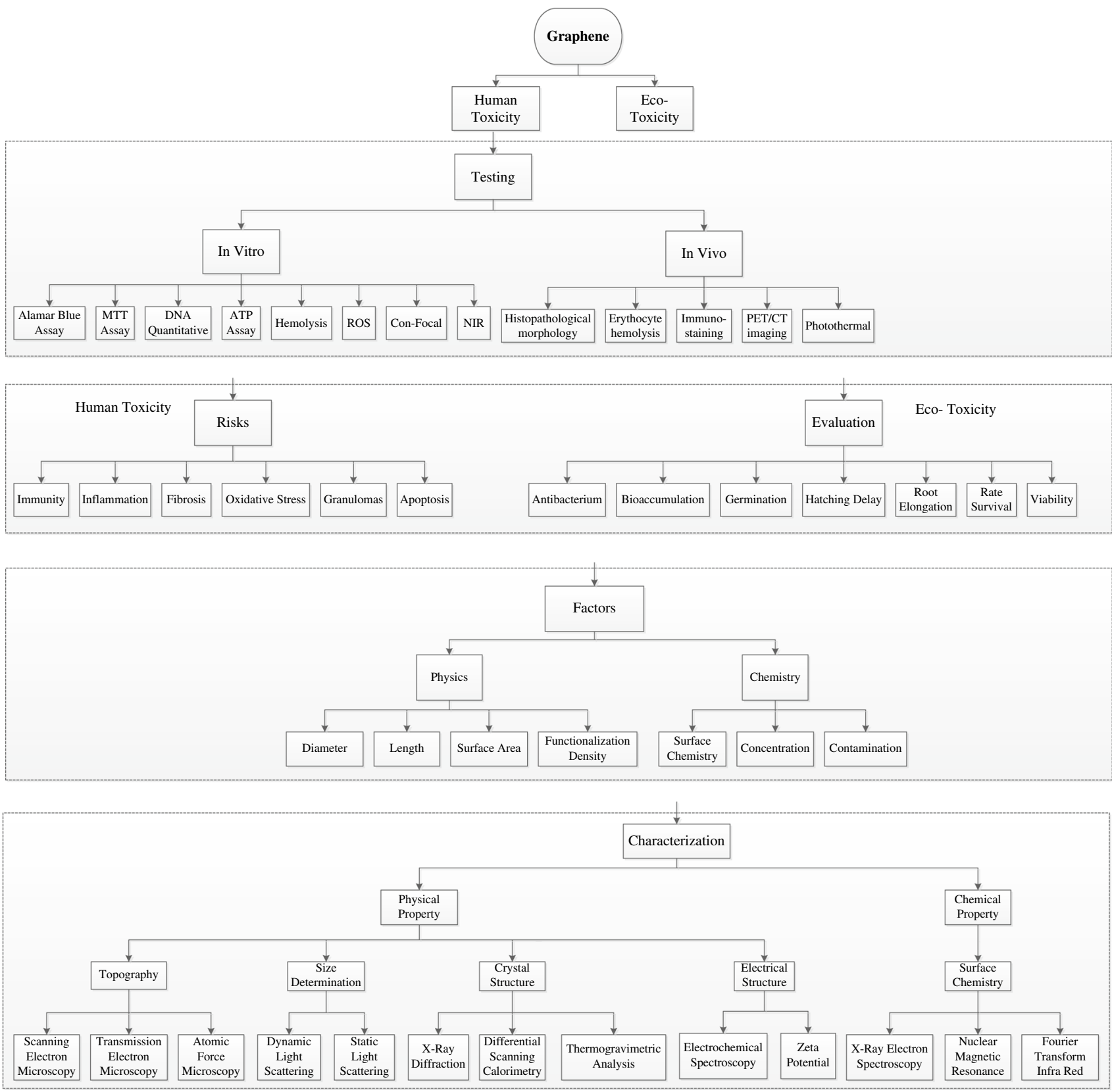

Fig. 5 Toxicology of graphene: An overview on the principal components of graphene toxicity

identify the nature of adverse effects and quantitatively define dose effects and dose-response relationships. All of the most recent reviews focus on the most important aspects of the risk assessment of graphene-based nanomaterials, which determine the extent to which the range of concentration of a given chemical released into the environment (e.g., level of exposure) overlaps in time and space with those that are toxic (e.g., hazardous to health) in a range of selected organisms in a given populations within the ecosystem. Considering factors such as exposure and medical treatments and due to the different variables, it is required to be very precise to consider the best graphene based nanomaterials. Such variables are often complex and are complicated further by established ecosystems, and the numerous inter-relationships, and multivariant pathways in the distribution of chemicals and nanoparticles in the natural environment (Toxicology 1990).

Hazard assessment of carbon-based nanomaterials

Hazard assurance that a chemical or nanoparticle can show up in the tissue of the host and any other living organism 
Injection

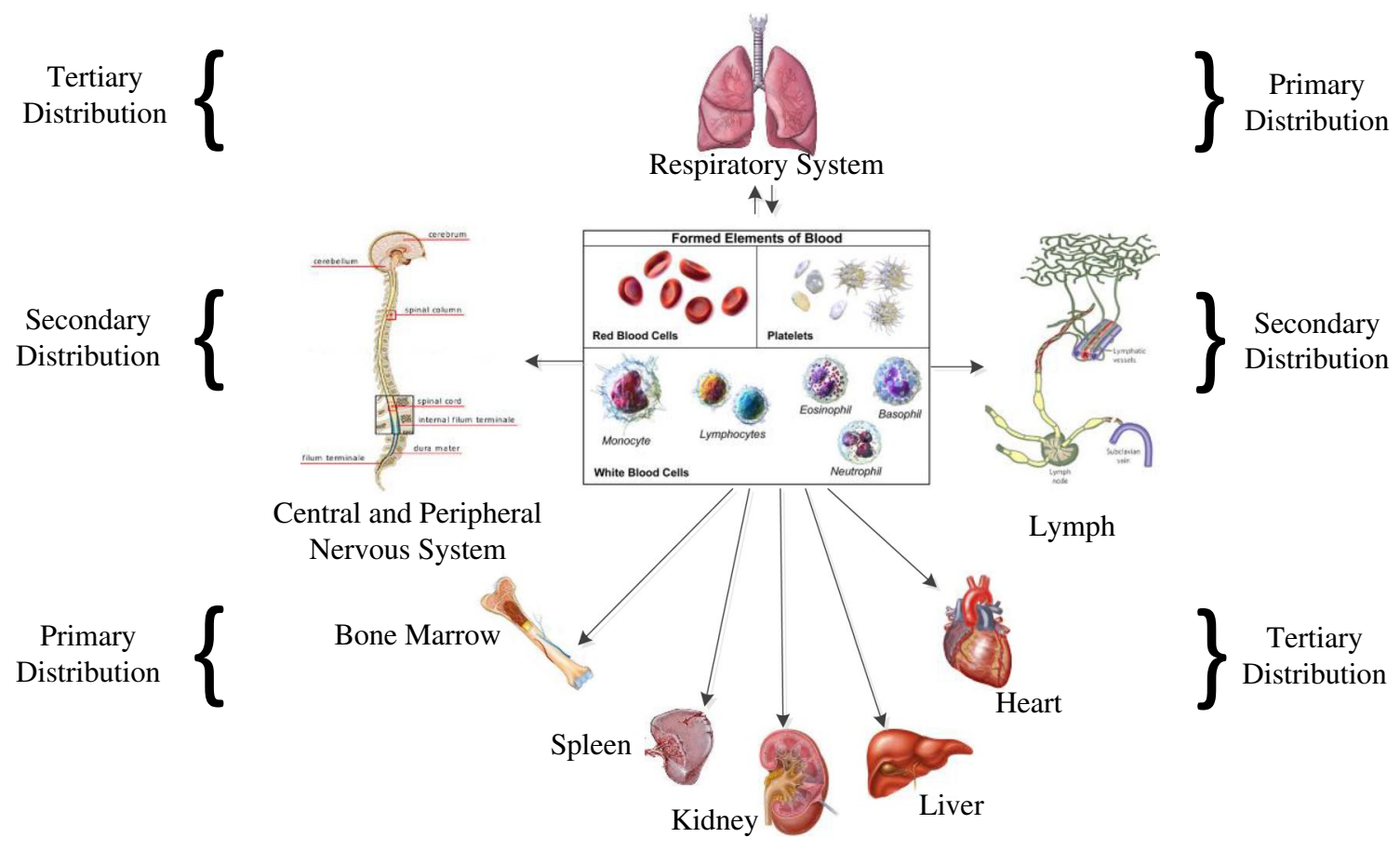

Fig. 6 Distribution of graphene in the body

is usually dependent upon the frequency, concentration, and duration of exposure of the materials due to factors including the magnitude, extent, and duration to cause toxic side effects. Individual assessments and combinatorial hazard assessments are now required, and are in great demand to identify and characterize the causative agents. This is primary due to exposure (as described previously), as a result of environment toxicity or in vitro or in vivo medical treatments using graphene either as an implantable device or as drug delivery carrier. Animal experiments are performed according to policy guidelines standardized by the Organization for Economic Co-operation and Development (OECD) in the UK, and are known to determine common toxic characteristics of a broad range of materials and chemicals. This includes eco-toxicity or animal and human toxicity.

\section{Animal and human toxicity}

Toxicology studies are now becoming more advanced in small- and large-scale animal studies in vivo and human cell lines in vitro. Direct hazard assessments and current methodology for studying nanomaterials help to reveal gaps in the knowledge and deficiency of current assessments. For example, the lethal dose (LD50) of graphite, CNTs, and fullerenes reported as $2 \mathrm{~g} / \mathrm{Kg}$ (Sebastian 2012), $2 \mathrm{mg} / \mathrm{Kg}$ (Ragot et al. 2010), and 1.2 g/Kg (Da Ros et al. 2001), respectively, in animals. It is essential to employ traditional risk assessments and control of substances hazardous to health (COSHH) procedures when dealing with engineered nanoparticles, as information from toxicology studies is often deficient for broad risk assessments to be made with regard to nanomaterials based on carbon due to their vast heterogeneity. The most common cytotoxicity assays to evaluate toxicity of graphene-related materials are apoptosis assay's such as caspase-3,7 assays to measure cell death, cell adhesion and morphology, cytokine detection, hemocompatibility, hemolysis; lactate dehydrogenase (LDH) assay to assess membrane integrity; methyl thiazolyl tetrazolium (MTT) assay as a measure of metabolic activity, platelet activation, ROS generation, and genotoxicity (Bitounis et al. 2013; Vallabani et al. 2011; Zhang et al. 2010b; Schinwald et al. 2012; Chang et al. 2011b; Akhavan et al. 2012d; Liao et al. 2011; Sasidharan et al. 2012; Seabra et al. 2014). Since there is a very close relationship between mutation and damage to DNA, genotoxicity assays are considered as an early and important indicator of toxicity, which may lead to cancer and tumor development (Agemy et al. 2010). The MTT is perhaps the most popular assay among the cell-based assays, and used for cytotoxicity and cell viability when characterizing nanomaterials. In addition, this method using CNTs as the test substrate has been reported to be problematic as a consequence of using graphene-based materials (Bitounis et al. 2013; Liao et al. 2011; Seabra et al. 2014). Therefore, 
the cell proliferation assay (WST-8) is a preferred method instead of MTT (Liao et al. 2011). Thus, the most appropriate cytotoxic assays must be used to evaluate the toxicity of graphene-based materials to avoid false data. Graphenebased nanomaterials' in vivo studies are mostly based on the evaluation of tissue distribution (bioaccumulation) and excretion from the body. The most common animal model used to evaluate in vivo toxicity of graphene-based materials is the Zebrafish model (Fako and Furgeson 2009). The route of administration should be considered as an important parameter that impacts the toxicity of nanomaterials (Yang et al. 2013a). Based on the recent literature, it is clear that due to the increase in the importance of graphene-based materials, meticulous and accurate in vitro and in vivo studies and accurate testing models of toxicity of the growing graphene family are required and are now in great demand.

\section{Eco-toxicity of graphene-based nanomaterials}

Above all other living creatures on the earth, continual evolution brought intelligence to mankind. Therefore, it is necessary that the study of eco-toxicological hazards and their assessments are of considerable importance. In toxicology, the focus is on human as a species, but in ecotoxicology the focus is broadened significantly, regarding the safety and well-being of millions of other common and rare species. So environment factors could put human needs at risk due to indirectly addressing the safety of harmful chemicals, which can degrade or even destroy ecosystem (Toxicology 1990). The terrestrial environment is similar ecologically to aquatic environments, because living organisms are often intertwined and share a common food chain associated with their natural environment. Two of the well-known organized biological communities are the plant and animal kingdom. The plants are almost affected directly by the level of exposure and the presence of pollutants in the air and in rain fall. However, animals and sometimes humans can become contaminated with heavy metals by uptake toxic compounds through the food chain, e.g., mercury compounds. In the aquatic ecosystem, there is direct contact between the pelagic fauna and flora with the chemicals suspended or dissolved in water. In contrast, the food chain is considered as indirect contamination or deemed much slower than direct contamination. Both ecosystems can be contaminated by direct exposure or ingestion of the particles. The quantities of chemical substances, which are carried by different media, such as in the air, soil, or water, are often variable in nature. Furthermore, in different media the bioavailability and dynamics are very different. Eventually, such variability and different approaches applied for terrestrial and aquatic organisms raise substantial concerns in terms of accurately determining the levels of toxicity when comparing similar ecosystems.

\section{Toxicity of functionalized graphene oxide and functionalized graphene}

There are very few reports available on the toxicity of graphene in vitro (Liu et al. 2009; Singh et al. 2011; Sasidharan et al. 2011) and in vivo (Chang et al. 2011a; Yang et al. 2011a, b) compared to carbon nanostructures, fullerenes (Service 2003), and CNTs (Nakamura and Isobe 2003; Lacerda et al. 2006). The main parameters affecting cytotoxicity of this class of nanomaterial including graphene (Wang et al. 2010), GO (Hu et al. 2010), CNTs (Chang et al. 2011a; Lam et al. 2006), gold and silver nanoparticles (Lee et al. 2011) in vitro and in vivo are concentration, shape, size, surface charge, energy, and wettability. Also, in vitro studies could be divided in two discrete sections: (1) cytotoxicity and (2) genotoxicity. Extensive studies have been performed relating to in vitro cytotoxicity of GO over the last 5 years. However, the investigation of new areas of concern relating to genotoxicity of nanomaterials is an important research theme, as there is a close correlation between DNA damage, mutation, and the formation of cancers (Agemy et al. 2010). There is insufficient research carried out on the genotoxicity of graphene-based materials at present and warrants much further investigation.

\section{Toxicity of functionalized GO}

GO is water-soluble nanomaterial and has been investigated extensively as a material for industrial applications for electronics and use in biomedical engineering. This is due to the large vacancy of planar surface area for efficient filling of aromatic drug molecules through $\pi-\pi$ stacking interactions, and carboxyl $(-\mathrm{COOH})$, epoxy $(-\mathrm{C}-\mathrm{O}-\mathrm{C}-)$, and hydroxyl $(-\mathrm{OH})$ functional groups. Moreover, limitation of GO use in a variety of biomedical applications is due to the absence of stable dispersions. In the following sections, we review current nanotoxicity studies carried out with GO over the last 5 years. Moreover, Tables 1 and 2 provide a thorough summary of all of the current studies, which address functionalized GO cytotoxicity from in vitro and in vivo studies.

\section{Functionalized graphene oxide toxicity in vitro}

GO cytotoxicity Initially, the influence of GO on the viability of A549 (human lung adenocarcinoma epithelial cell line) cells based on current data has shown that at low concentrations, GO does not enter into the cells and shows no signs of cytotoxicity. However, GO is known to be cytotoxic and is dose-dependent and known to cause oxidative stress in A549 cells, and induce a loss in cell viability at high concentrations (Chang et al. 2011a). Cell viability tests depict significant cell destruction by $1.0 \mu \mathrm{g} / \mathrm{mL}$ 


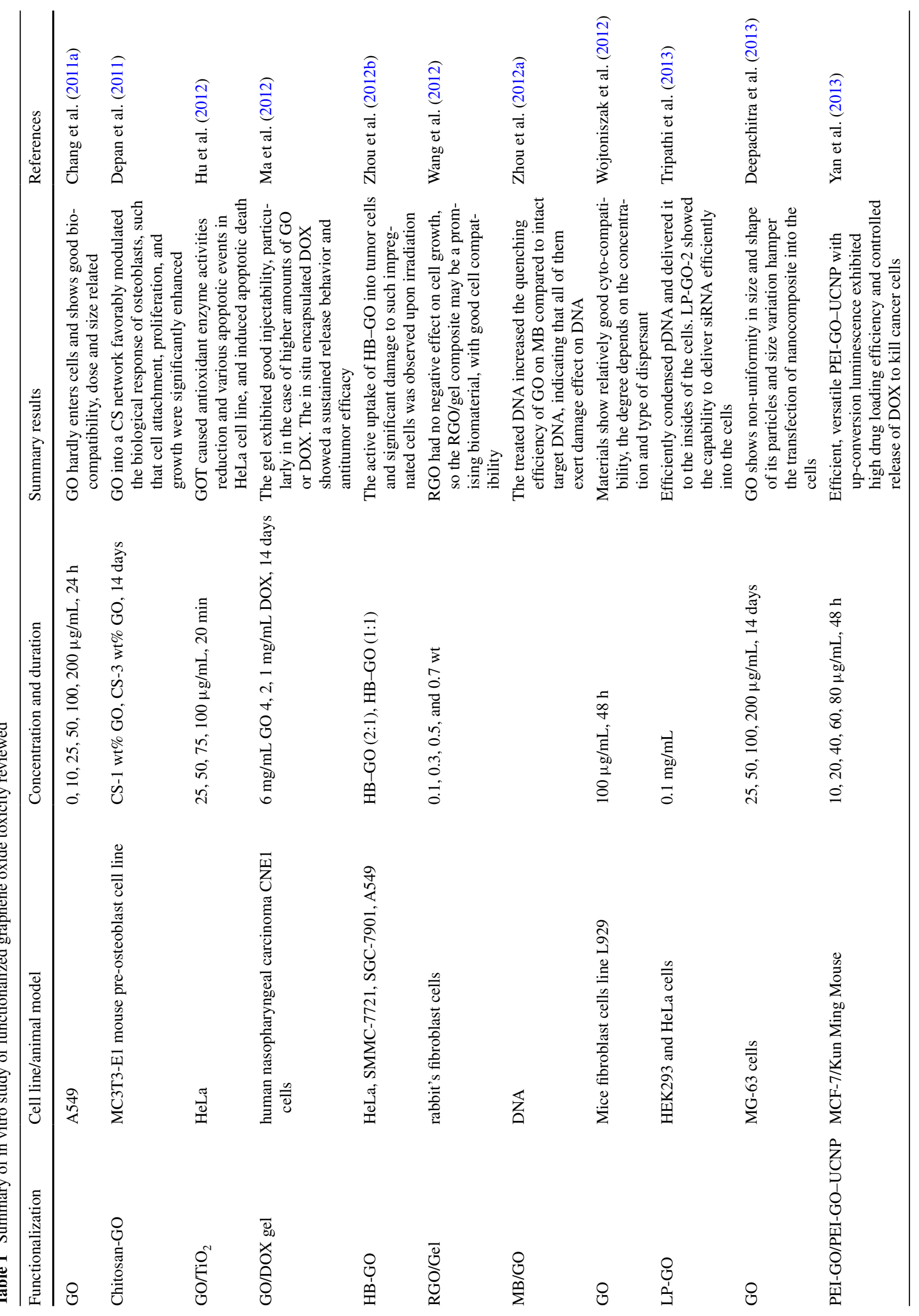




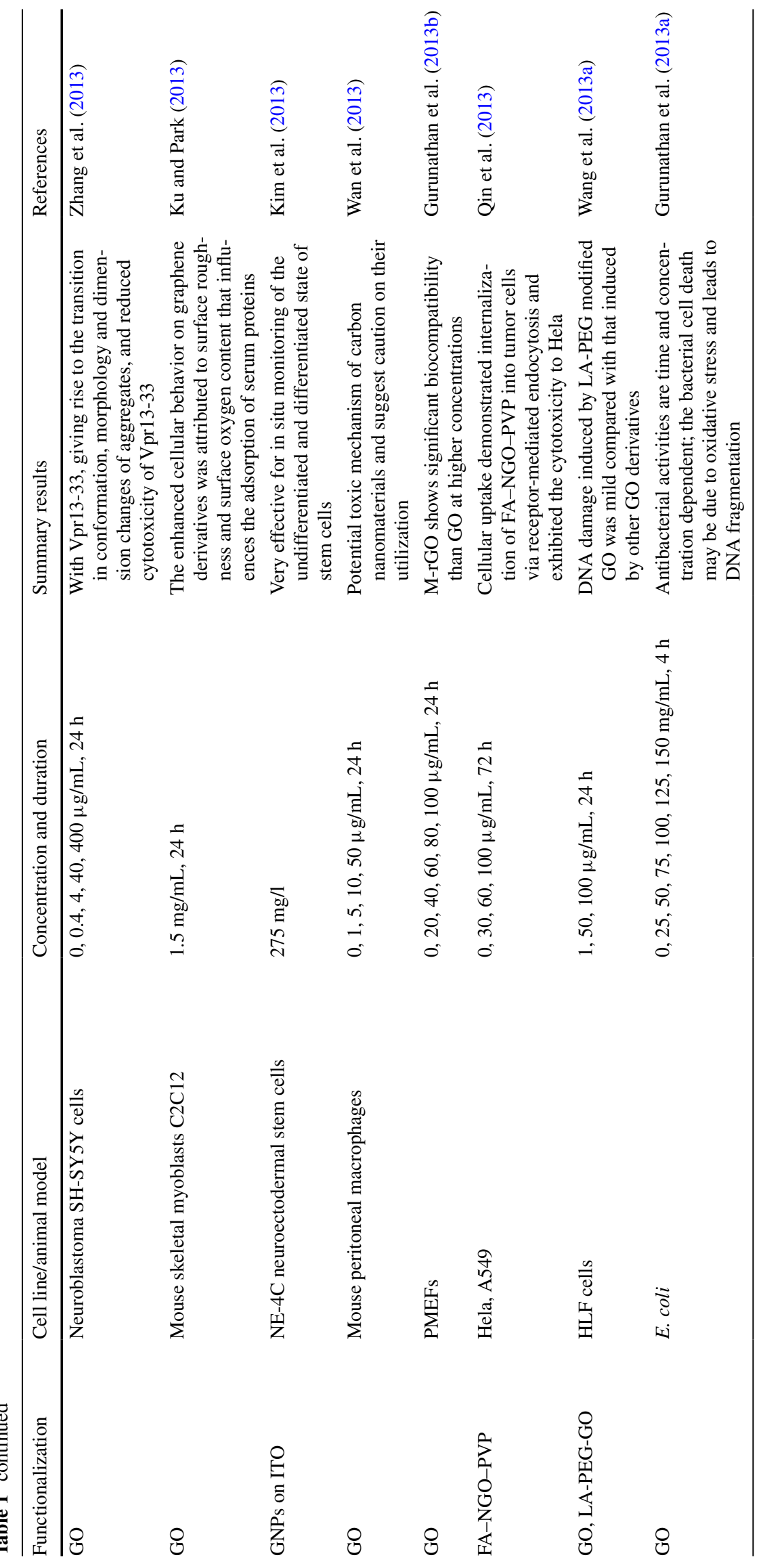




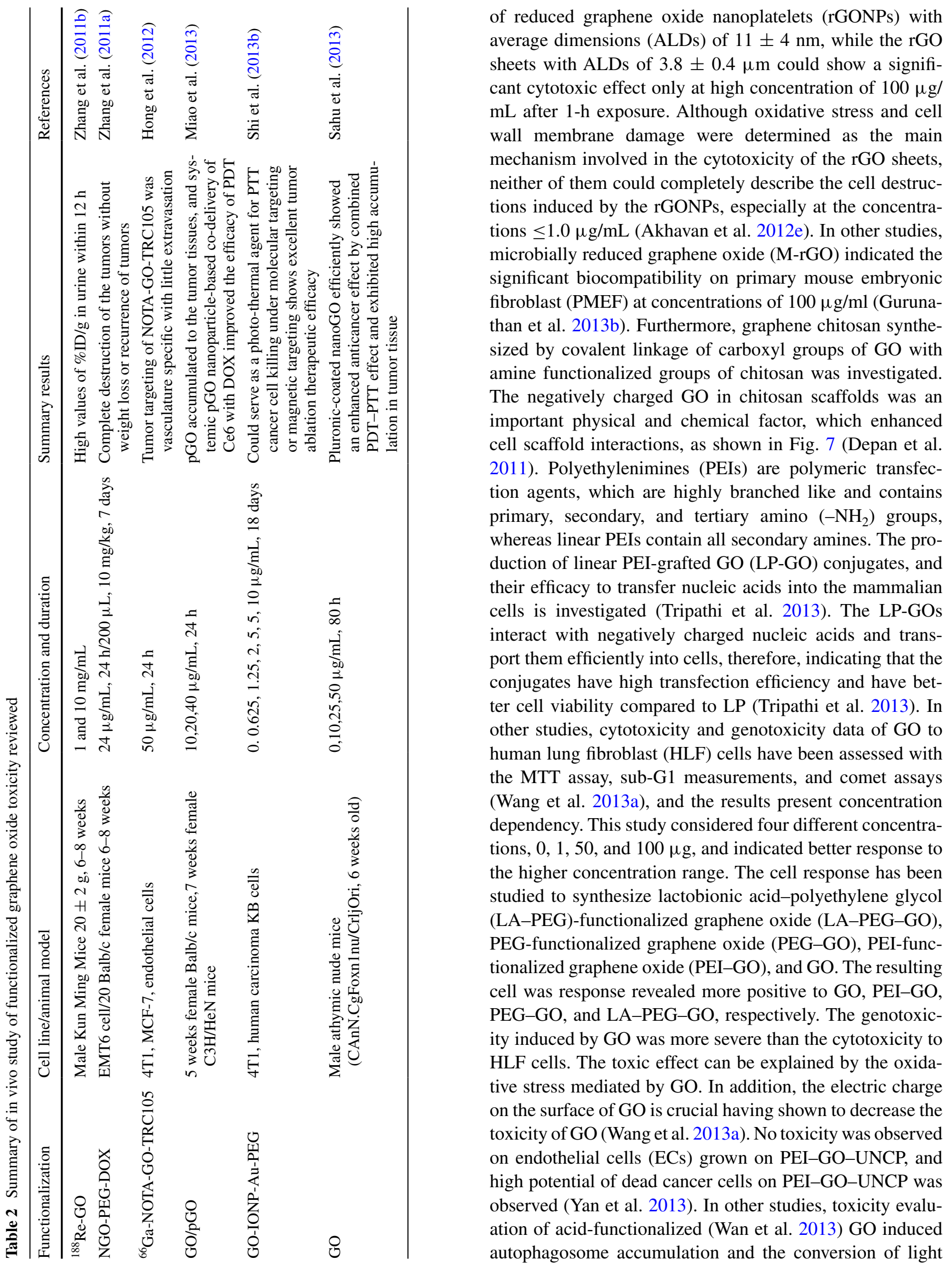



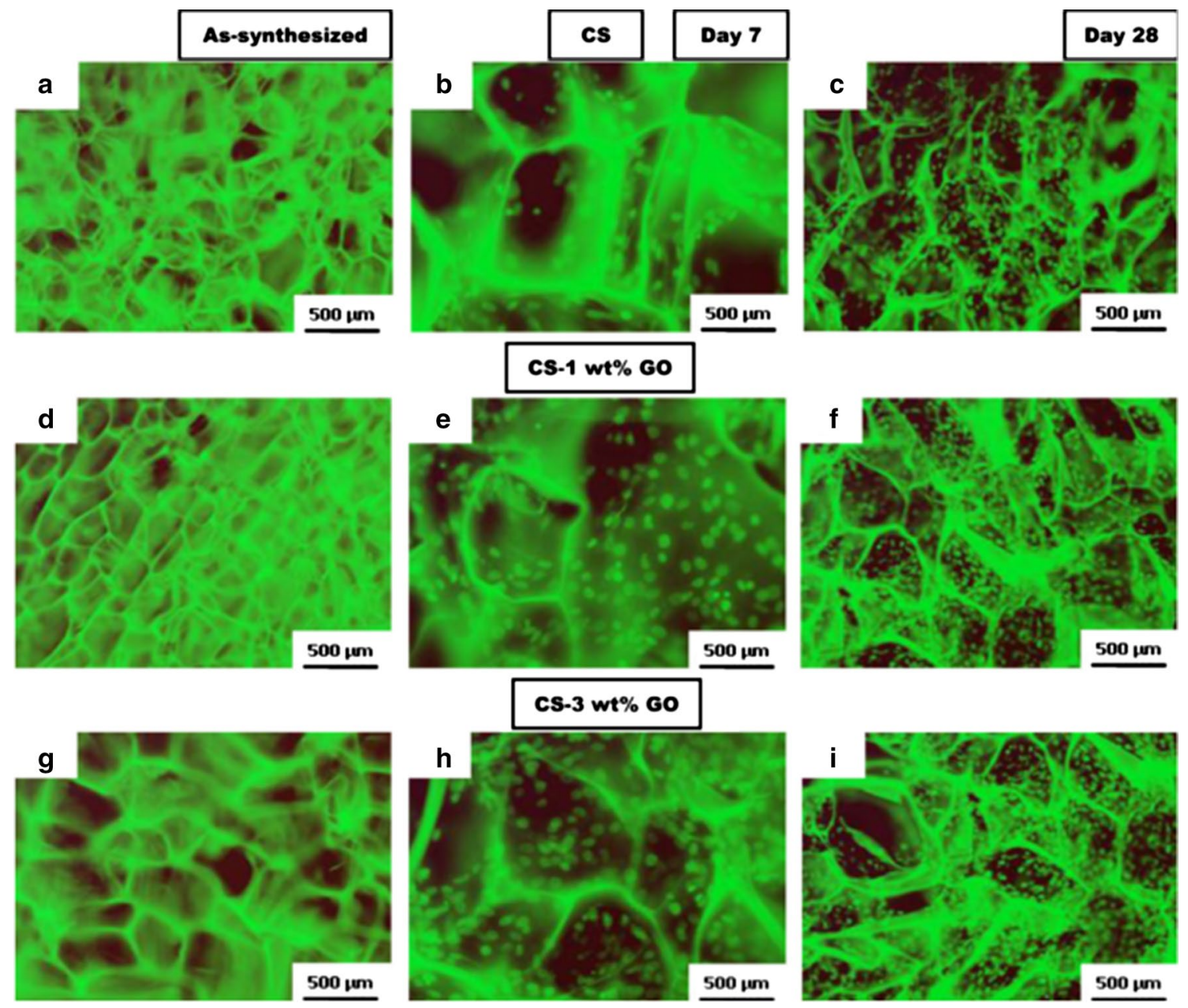

Fig. 7 a-i Fluorescence micrographs illustrating the proliferation of pre-osteoblasts on pure CS and CS-GO scaffolds at similar locations (e.g., the center) after 7 and 28 days, respectively (Depan et al. 2011)

chain 3 (LC3-I) to LC3-II (LC3 represents a mammalian homologue of the yeast autophagy-related gene ATG8). In addition, GO accumulation in macrophage lysosomes indicates the instability of lysosome membranes and leads to autophagic degradation (Wan et al. 2013). An investigation showed that GO was capable of stimulating myogenic differentiation and revealed myotube formation on $\mathrm{GO}(\mathrm{Ku}$ and Park 2013). In this case, myogenic differentiation was significantly enhanced on GO base on the protein expression, formation, and expression of differentiation specific genes (MyoD, myogenin, Troponin T, and MHC). So the results indicated that the potential application for skeletal tissue engineering of GO is to stimulate myogenic differentiation (Ku and Park 2013). A further study investigated how PTT influenced cytotoxicity when using polyvinylpyrrolidone (PVP) functionalized GO (Qin et al. 2013). Here, folic acid (FA), a target molecule to cancer cells, was conjugated to $\mathrm{GO}$ via covalent $-\mathrm{NH}_{2}$ bonds, obtaining $\mathrm{FA}-\mathrm{NGO}-$ $\mathrm{PVP}$ and then illustrating an ideal $\mathrm{pH}$-responsive nanocar- rier for delivery of an anticancer drug doxorubicin (DOX) with the loading ratio more than $100 \%$ (Qin et al. 2013). In other studies, $\mathrm{GO}$, titanium dioxide $\left(\mathrm{TiO}_{2}\right)\left(\mathrm{GO} / \mathrm{TiO}_{2}\right)$ hybrid (GOT) was studied by using $\mathrm{Ti}\left(\mathrm{OC}_{4} \mathrm{H}_{9}\right)_{4}$ and $\mathrm{GO}$ as reactants. The result presented no toxicity of GO in vitro as an electron sink in GOT efficiently increased the photodynamic therapy (PDT) activity (Hu et al. 2012). Furthermore, in vitro studies of fibrin-coated GO (FGO) indicated that high levels of alkaline phosphatase and calcium ion release lead to confirmation of osteo-inductive nature of FGO (Deepachitra et al. 2013), and MTT assay data showed the biocompatibility of osteoblast-like cell line MG-63 on GO. Furthermore, GO nanosheets used to induce in situ gelation of doxorubicin hydrochloride as an anti-tumor drug (Ma et al. 2012). Introduction of small amount of GO into aqueous solutions of doxorubicin hydrochloride caused the formation of thixotropic gel without any chemical additives (Ma et al. 2012). Cell growth confirmed that the materials remained cytocompatible with GO-based materials. 
Genotoxicity of graphene-based nanomaterials Investigations using nanoparticles less than $50 \mathrm{~nm}$ in each dimension, and GO with a lateral dimension of $2 \mu \mathrm{m}$ and $1.5 \mathrm{~nm}$ in thickness at different concentrations were dependent factors in inducing genotoxicity, and graphene was found to cause the most damage to DNA (Qiao et al. 2013). A further study depicted DNA damage using nanoparticles of silicon dioxide $\left(\mathrm{SiO}_{2}\right), \mathrm{ZnO}, \mathrm{TiO}_{2}$, tin $(\mathrm{Sn})$, and CNTs at concentration higher than $(100 \mu \mathrm{g} / \mathrm{mL})$. Graphene concentrations higher than $1 \mu \mathrm{g} / \mathrm{mL}$ induced DNA damage at a significantly lower concentrations (Seabra et al. 2014; Qiao et al. 2013). Also the size-dependent genotoxic effects of rGO nanoplatelets (rGONPs) on mesenchymal stem cells (hMSCs) are investigated (Akhavan et al. 2012e). The rGONPs showed genotoxic effects on hMSCs through DNA fragmentation and chromosomal aberrations even at very low concentration of $0.1 \mathrm{mg} / \mathrm{mL}$, highlighting concerns when using stem cells for applications for use in regenerative medicine.

Functionalized GO toxicity in vivo Functionalized GO toxicity and their distribution have been studied in mice using radiolabeling techniques (Zhang et al. 2011b). Results indicate that GO has sufficient biocompatibility when studied in parallel with red blood cells (RBCs). In addition, GO mainly deposited in the lungs and surrounding tissue, and no pathological variation was illustrated when exposed to mice at $1 \mathrm{mg} / \mathrm{kg}$ body weight of GO for 14 days. But at a higher dosage, $10 \mathrm{mg} / \mathrm{kg}$ body weight, pulmonary edema, longtime retention, high accumulation, granuloma formation, inflammation, and cell infiltration was observed (Zhang et al. 2011b). Amino group termination covalently attached to GO via a six-arm branched glycol (PEG; $10 \mathrm{kDa}$ ) chains were conjugated to NOTA (1,4,7-triazacyclononane-1,4,7-triacetic acid, for ${ }^{66}$ Ga-labeling) and TRC105 (an antibody that binds to CD105) (Hong et al. 2012), and study of histology validated the characterization of the GO conjugates. The in vivo characterizations were performed in murine breast tumor mice (4T1), and great stability in mouse serum was exhibited in ${ }^{66} \mathrm{Ga}-\mathrm{NOTA}-\mathrm{GO}$ and ${ }^{66} \mathrm{Ga}$-NOTA-GO-TRC105 conjugates. Quick accumulation of ${ }^{66} \mathrm{Ga}-\mathrm{NOTA}-\mathrm{GO}-\mathrm{TRC} 105$ in tumor uptake remained stable (Hong et al. 2012). In another study, GO functionalization by iron oxide nanoparticles (IONPs) and gold, forming a multi-functional magnetic and plasmonic GO-IONP-Au nanocomposite with strong superparamagnetism, significantly enhanced optical absorbance in the NIR region (Shi et al. 2013b). Enhanced photo-thermal cancer ablation effect using GO-IONP-Au-PEG is realized in comparison with PEGylated GO used in earlier studies, as demonstrated in in vivo animal experiments. Moreover, the IONP and Au compartments in the GO-IONP-Au-PEG nanocomposite could prove to be advantageous for magnetic resonance (MR) and X-ray dual-modal imaging (Shi et al. 2013b). Non-covalently functionalized nanographene oxide sheet (nano-GO) with pluronic block copolymer and positively charged photosensitizers via electrostatic interactions have been previously reported (Sahu et al. 2013). These applications were combined with photodynamic thermal therapy (PDT) and PTT for cancer. Cancer cells show increased uptake when compared to normal cells by the use of the nanoGO, and it showed no toxicity to cells in the absence of NIR. High tumor accumulation was observed as a complex was injected intravenously into the tumor. Then, total ablation of tissue caused by NIR explosion via PDT and PTT (Sahu et al. 2013). In further studies, it was shown that doxorubicin loaded on to polyethylene glycol (PEG)ylated graphene oxide (GO-PEG-DOX) facilitates combined chemotherapy and PTT (Zhang et al. 2011a). The GO-PEG-DOX nanoparticle ability to combine local, site-specific chemotherapy with external near-infrared-photo-thermal therapy (NIR-PTT) significantly improved the therapeutic efficacy of cancer treatment. In addition, the pathologic examination of main organs improved, as their toxicity study showed less toxicity results with GO-PEG-DOX compared to DOX (Zhang et al. 2011a). Furthermore, injection of $80 \mathrm{mg} / \mathrm{kg}$ polyethylene glycol-grafted graphene oxide (PEG-GO) into mice intravenously was investigated (Miao et al. 2013) and demonstrated the enhancement of cellular delivery compared to chlorin e6 (Ce6), as a natural molecule, and a promising photosensitizer. Accumulation of Ce6/Dox/PEG-GO in tumor tissues is shown in molecular imaging of mice, and substantial disruption of tumor nuclei was observed (Miao et al. 2013). Furthermore, photosensitizer molecule, 2-(1-hexyloxyethyl)2-devinyl pyropheophorbide-alpha (HPPH or Photochlor ${ }^{\circledR}$ ) loaded onto PEG-functionalized graphene oxide (GO) via supramolecular $\pi-\pi$ stacking investigated and obtained GOPEG-HPPH complex, shows high HPPH loading efficiency. The in vivo distribution and delivery were tracked by fluorescence imaging as well as positron emission tomography (PET) after radiolabeling of $\mathrm{HPPH}$ with ${ }^{64} \mathrm{Cu}$. Compared with free HPPH, GO-PEG-HPPH offers dramatically improved photodynamic cancer cell killing efficacy due to the increased tumor delivery of HPPH (Rong et al. 2014). In vivo biodistribution, and potential toxicity of as-made GO and a number of polyethylene glycol (PEG)-functionalized GO derivatives with different sizes and surface coatings, after oral and intraperitoneal administration at high doses are investigated (Yang et al. 2013a). Insignificant tissue uptake via oral administration on ${ }^{125}$ I-labeled PEGylated GO derivatives is observed, indicating the rather limited intestinal adsorption of those nanomaterials. In contrast, PEGyalted GO derivatives highly accumulated, but not as-made GO, in the reticuloendothelial (RES) system including liver and spleen were observed post-injection (i.p.) and are highlighted in Fig. 8. Moreover, studies based on histological examination of organ slices and hematological analysis discovered that insignificant toxicity to the treated animals, although GO and PEGylated GO 


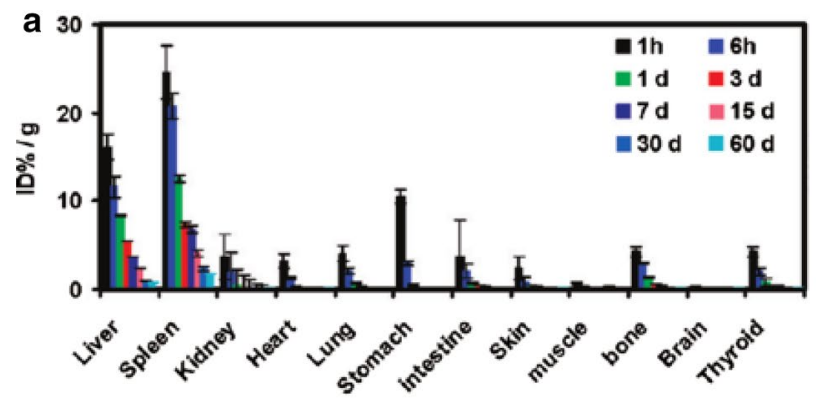

C

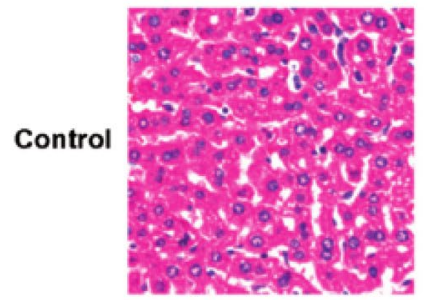

f

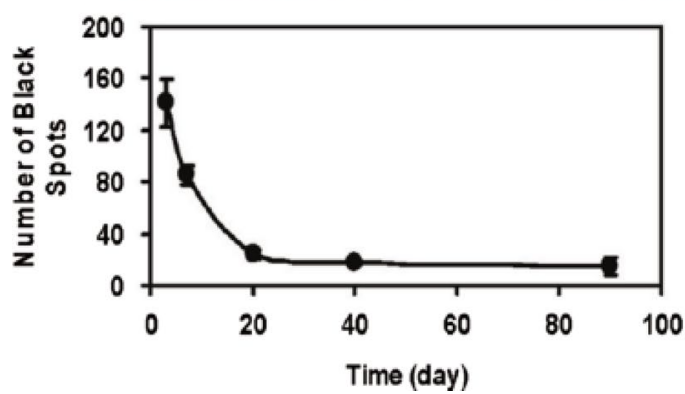

d

$3 d$
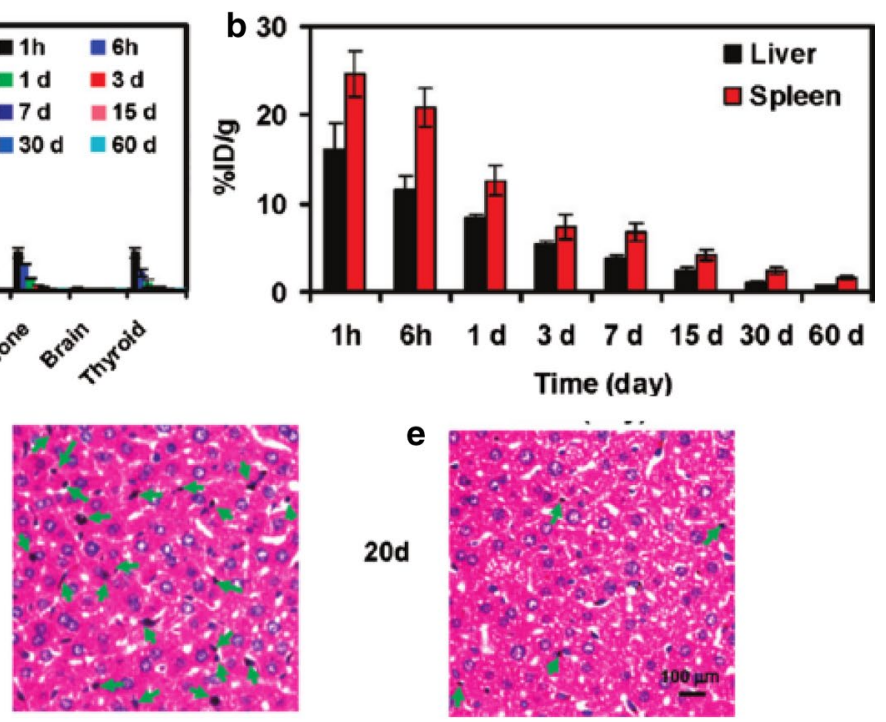

e
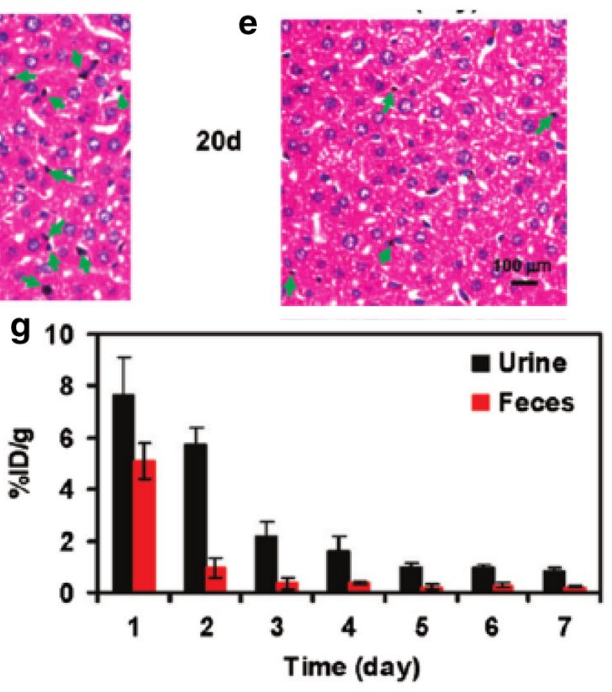

Fig. 8 Biodistribution and clearance of NGS-PEG. a Time-dependent biodistribution of ${ }^{125} \mathrm{I}-\mathrm{NGS}-\mathrm{PEG}$ in female $\mathrm{Bal} \mathrm{b/c}$ mice. b ${ }^{125}$ I-NGS-PEG levels in the liver and spleen over time. c-e H\&E stained liver slices from the untreated control mice (c) and NGSPEG injected mice at 3 days (d) and 20 days (e) p.i. Brown-black spots which could be clearly differentiated from the blue-stained cell nuclei were noted in the liver of mice 3 days after injection of graphene. Much less black spots in the liver were observed 20 days later.

derivatives were retained in the mouse over a long period of time after post-injection (Yang et al. 2013a).

Toxicity of functionalized graphene

Among the graphene-based materials, graphene due to its super hydrophobicity is potentially more toxic than GO. However, this can be lessened by functionalizing graphene with polar chemical groups, which could aid the water solubility of graphene. In the following sections, we review the toxicity studies based on functionalized graphene (represented in Table 3 ) to present a summary of in vitro functionalized graphene toxicity.

\section{Functionalized graphene toxicity in vitro}

Cytotoxicity of functionalized graphene In vitro toxicity studies with graphene revealed better results compared f Statistic of black spot numbers in liver slices at various time postinjection of NGS-PEG. Numbers of spots in full image fields under a $\times 20$ objective were averaged over 5 images at each data point. $\mathbf{g}$ ${ }^{125}$ I-NGS-PEG levels in urine and feces in the first week after injection. Mouse excretions were collected by metabolism cages. Error bars in the above data were based on standard deviations of 4-5 mice per group (Yang et al. 2011a, b)

to CNTs in inducing PTT to destroy the human glioma cells, U251 cell line (Markovic et al. 2011). This involved oxidative stress and mitochondrial membrane depolarization resulting in mixed apoptotic and necrotic cell death characterized by caspase activation/DNA fragmentation and cell membrane damage, respectively (Markovic et al. 2011). In a further study, isobaric tags were used for relative and absolute quantification (iTRAQ)-coupled 2D liquid chromatography-tandem mass spectrometry (LC-MS/ MS) approach to analyze the treated protein profile change in human hepatoma cells (HepG2) with graphene. The results showed less toxicity for moderate variation of protein levels for the cells treated with graphene (Yuan et al. 2011). Mouse induced pluripotent stem cell (iPSCs) culture and spontaneous differentiation into ectodermal and mesodermal lineages supported by graphene was investigated (Chen et al. 2012b). Graphene surface illustrated similar cell proliferation and adhesion of iPSC compared 


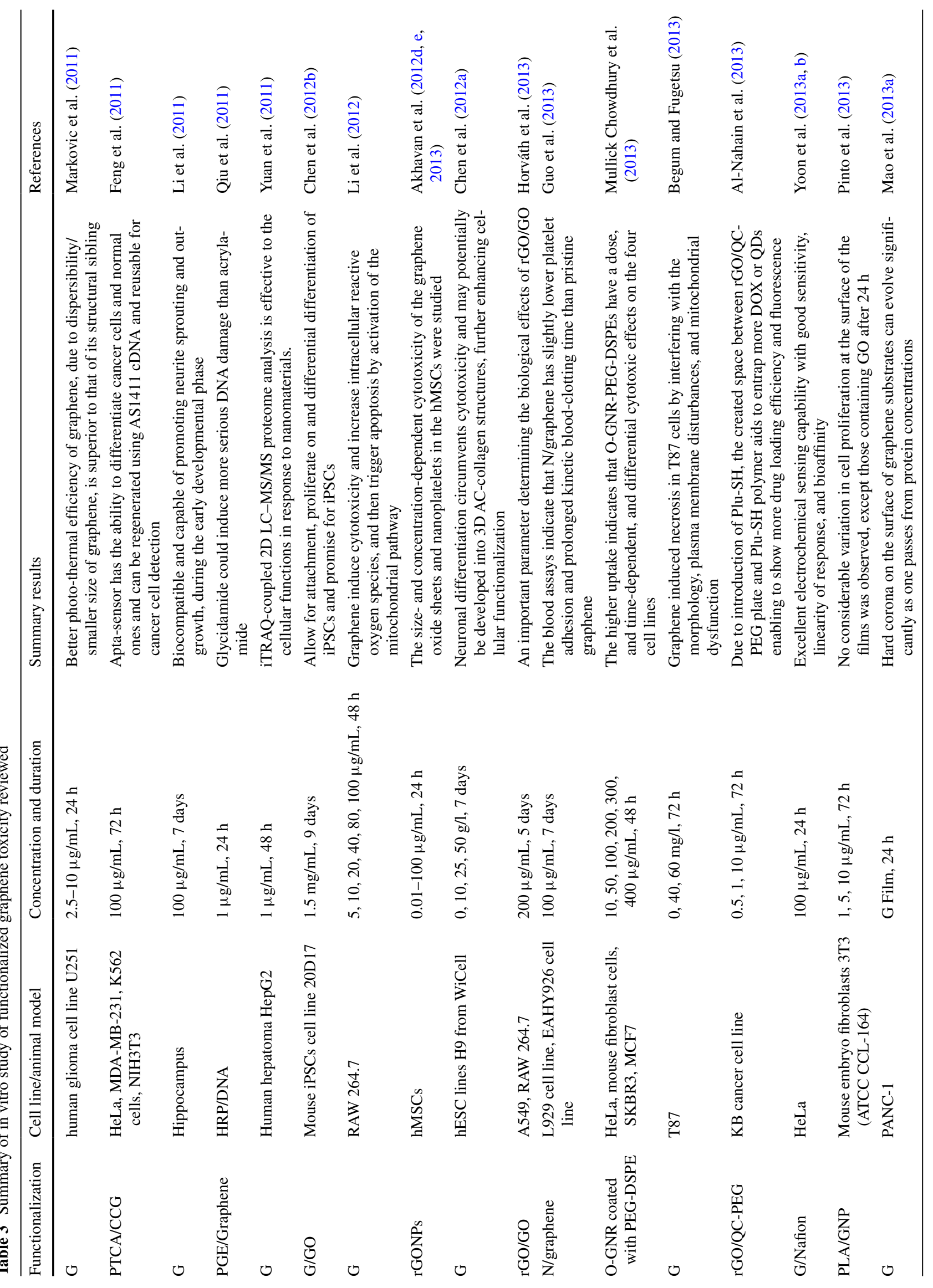


to glass substrates. Cytotoxicity effect-reduced graphene oxide nanoplatelets (rGONPs) on the human mesenchymal stem cells (hMSCs) were investigated (Akhavan et al. 2012e). The cell viability measurement indicated cell destructions at $1.0 \mu \mathrm{g} / \mathrm{mL}$ rGONPs; in contrast, the rGO sheets at concentration of $100 \mu \mathrm{g} / \mathrm{mL}$ illustrated a significant cytotoxic effect (Akhavan et al. 2012e). A further investigation using a single-layer-reduced GO nanoribbons (rGONRs) produced via an oxidative unzipping of MWCNTs (Akhavan et al. 2013). The cell viability assay on hMSCs with concentration of $10 \mu \mathrm{g} / \mathrm{mL}$ rGONRs indicated significant cytotoxicity effects, while the rGO sheets showed similar cytotoxicity at concentration of $100 \mu \mathrm{g} /$ $\mathrm{mL}$. The results illustrate the penetration of rGONRs into the cells and DNA fragmentation, as well as, chromosomal aberrations at concentrations of $1.0 \mu \mathrm{g} / \mathrm{mL}$ (Akhavan et al. 2013). The toxicity of graphene on macrophages and epithelial cells was also investigated. The results indicate that the initial exposure to these materials is most prominent in respiratory system (Horváth et al. 2013). The interaction of nitrogen ion-implanted graphene (NGR) has been evaluated with mouse fibroblast cells and human endothelial cells, as well as in blood compatibility studies using rabbit blood (Guo et al. 2013). The results indicated the cell viability and proliferation improvement of cells cultured on NGR compared with cells cultured on pristine graphene. Lower platelet adhesion, prolonged kinetic blood-clotting time, and hemolytic rate (below $5 \%$ ) presented for NGR showed thrombo-resistance than pristine graphene (Guo et al. 2013). The cytotoxicity of oxidized graphene nanoribbons (O-GNRs) water soluble with PEG-DSPE (1,2-distearoyl-sn-glycero-3-phosphoethanolamine- $N$-[amino(polyethylene glycol)]) was investigated (Mullick Chowdhury et al. 2013). The assays were conducted on Sloan-Kettering breast cancer cells (SKBR3), Henrietta Lacks cells (HeLa) derived from cervical cancer tissue, Michigan cancer foundation-7 breast cancer cells (MCF7), and National Institute of Health 3T3 mouse fibroblast cells (NIH-3T3) (Mullick Chowdhury et al. 2013). All of the cells decrease in cell viability, as they represented a time-dependent (12-48 h) and dose-dependent (10-400 $\mu \mathrm{g} / \mathrm{mL})$ response. It was found that SKBR3 and MCF7 show a significantly lowered cytotoxicity compared to HeLa cells. The cells incubated at $10 \mu \mathrm{g} / \mathrm{mL}$ concentration were $100 \%$ viable. As the concentration increased to $400 \mu \mathrm{g} / \mathrm{mL}$, the cell viability decreased to $\sim 78 \%$ of cells. On the other hand, significant dead cells were observed for HeLa cells even at concentration $10 \mu \mathrm{g} / \mathrm{mL}$. The results indicated the heterogeneous cytotoxicity of O-GNR-PEGDSPEs, which possessed different cytotoxicity compared with chemically reduced graphene (Mullick Chowdhury et al. 2013). In a related study, composite poly (lactic acid) (PLA) and PLA film filled with graphene-based materi- 
als investigated the biocompatibility. Graphene concentration of $10 \mu \mathrm{g} / \mathrm{mL}$ was used for mouse embryo fibroblasts incubated with both fillers. The results illustrate concentrations of graphene, and GO may perform decreased in toxicity biomedical applications (Pinto et al. 2013). Study of methotrexate (MTX) attached to the gelatin graphene nanosheets (gelatin-GNS) through strong $\pi-\pi$ stacking interactions was conducted (An et al. 2013), and depicted great ability as a drug release, and high drug loading capacity of MTX. Based on the cytotoxicity results on A549 cell, the gelatin-GNS showed non-toxic at specific concentration while the MTX-gelatin-GNS depicted biocompatibility (An et al. 2013). Another study showed that protein-based facile method for fabrication of nanosized, reduced graphene oxide (nano-rGO) with high stability and low cytotoxicity was also investigated (Sheng et al. 2013). Highly integrated constructed photo-acoustic/ultrasonic dual modality imaging and photo-thermal therapy platforms further demonstrated that the prepared nanorGO can be used as ready-to-use theranostic agents for both photo-acoustic imaging and photo-thermal therapy without further surface modification. Intravenous administration of nano-rGO in tumor bearing mice showed rapid and significant photo-acoustic signal enhancement in the tumor region, indicating its excellence for passive targeting and photo-acoustic imaging. Meanwhile, using a continuous-wave near-infrared laser, cancer cells in vivo were efficiently ablated, due to the photo-thermal effect of nano-rGO (Sheng et al. 2013). Number of neurite on graphene after cell seeding were enhanced during 7 days compared with tissue culture polystyrene (TCP) substrates ( $\mathrm{Li}$ et al. 2011). In addition, the growth-associated protein-43 (GAP-43) was examined. Based on the results, GAP-43 expression was significantly enhanced in graphene when compared to TCP. This could result in the boost of neurite sprouting and outgrowth ( $\mathrm{Li}$ et al. 2011). In brief, the presence of graphene indicated in vitro biocompatibility with different cell lines based on previous investigations. In contrast, there are not many sufficient studies on in vivo biocompatibility, which needs more investigations in this emerging field. Moreover, by functionalizing graphene, as polymer filler, the surface topography changes, which causes an increase in roughness and surface energy to modify the wettability. The polar component of surface free energy increased with GO and decreased with graphene added to the polymeric matrix.

Genotoxicity studies Hemin-graphene nanosheets (H-GNs) that are able to distinguish intact and damaged DNA and catalytic activity of hemin through graphene $\pi-\pi$ interactions have successfully synthesized. Based on this, for detection of single-stranded DNA (ss-DNA) and damage DNA induced by chemicals such as styrene oxide (SO),
$\mathrm{NaAsO}_{2}$, and physical radiation, such as UV radiation, a free-label colorimetric method was developed. This method could be used to evaluate the new compounds' genotoxicity, the maximum limit of pesticide residue, and food additives, due to its simplicity, sensitivity, speed, and cost-effectiveness (Wei et al. 2013). Still, the molecular basis for in vivo graphene oxide (GO) toxicity is unclear. Caenorhabditis elegans has been used to investigate the microRNAs (miRNAs) control of GO toxicity. A total of 23 up-regulated and 8 down-regulated miRNAs in GO-exposed nematodes were identified with the aid of SOLiD sequencing. The miRNA mutants were confirmed by the functions of identified miRNAs in regulating the GO toxicity on lifespan. Furthermore, the evidence to raise a hypothesis that GO may reduce lifespan through influencing the functions of insulin/IGF signaling, TOR signaling, and germline signaling pathways controlled by miRNAs provided (Wu et al. 2014).

\section{Functionalized graphene toxicity in vivo}

There are no sufficient in vivo studies addressing the toxicity of graphene based on PubMed database. One of the current ongoing research themes is regarding the magnetization procedure and in situ reduction, which used to convert GO on to magnetic graphene. This was modified covalently to construct poly-acrylic acid (PAA) for linking the fluorescein $o$-methacrylate (FMA) to yield multifunctional graphene (MFG) with water dispersibility based on $2.5 \mathrm{mg} / \mathrm{mL}$ concentration (Gollavelli and Ling 2012). In vivo studies with zebra fish indicated no effect on the survival rate after MFG microinjection, nor any significant abnormalities. Meanwhile, in vivo studies on HeLa cells presented that MFG is a biocompatible imaging probe with concentrations in the range of $100 \mu \mathrm{g} / \mathrm{mL}$ (Gollavelli and Ling 2012). Graphene nanoparticle dispersions indicated the multifunctional agents for in vivo biomedical applications. Therefore, regulatory guidelines for pharmaceuticals is followed, which recommend safety pharmacology assessment at least 10-100 times higher than the projected therapeutic dose and present comprehensive single dose response, expanded acute toxicology, toxico-kinetics, and cardiovascular pharmacology results for intravenously administered dextran-coated GO nanoplatelets (GNPDex) formulations to rats at doses between 1 and $500 \mathrm{mg} /$ $\mathrm{kg}$ (Kanakia et al. 2014). The results presented that the maximum tolerable dose (MTD) of GNP-Dex is between $50 \mathrm{mg} / \mathrm{kg} \leq \mathrm{MTD}<125 \mathrm{mg} / \mathrm{kg}$ blood half-life $<30 \mathrm{~min}$, and majority of nanoparticles excreted within $24 \mathrm{~h}$ through feces. Histopathology changes were noted at $\geq 250 \mathrm{mg} / \mathrm{kg}$ in the heart, liver, lung, spleen, and kidney; no changes in the brain and no GNP-Dex-related effects in the cardiovascular parameters or hematological factors were found (blood, lipid, and metabolic panels) at doses $<125 \mathrm{mg} / \mathrm{kg}$ 

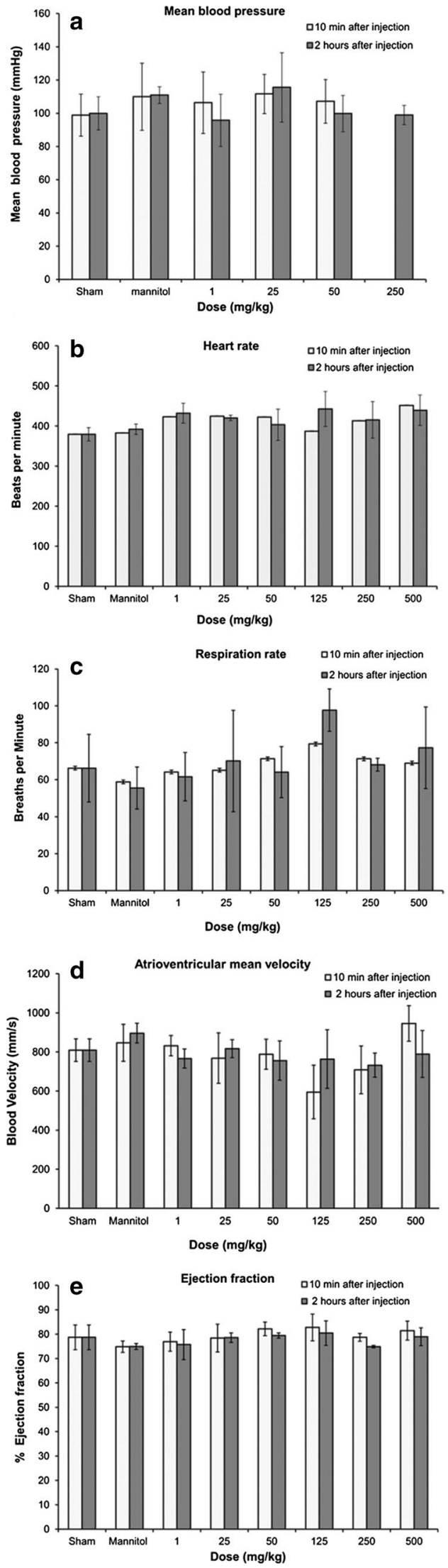

4Fig. 9 Hematological results from blood pressure and echocardiography measurements $10 \mathrm{~min}$ and $2 \mathrm{~h}$ post-injection of GNP-Dex (doses: $1-500 \mathrm{mg} / \mathrm{kg}$ ). a Blood pressure, b heart rate, $\mathbf{c}$ respiration rate, $\mathbf{d}$ atrioventricular mean blood velocity, e \% ejection fraction (Kanakia et al. 2014)

presented in Fig. 9. This result will open up new opportunities for pivotal preclinical single and repeat dose safety studies following good laboratory practices (GLP) as mandatory by regulatory agencies for investigational new drug (IND) applications (Kanakia et al. 2014).

\section{Conclusion}

Graphene-based nanomaterials have great potential for large number of future technologies ranging from biotechnological and biomedical applications including, drug delivery, PTT, and cancer targeting and therapy. Graphene materials are known to vary widely in terms of their physical and chemical properties such as their dimensions and chemical functional groups. Moreover, they possess unique physical and chemical material properties such as optical, electrical and thermal conductivity, and high surfaceto-volume ratio. In addition, they can be easily linked to macromolecules through covalent or non-covalent attachment. The types of graphene material and their chemical modifications to produce novel graphene compounds provide different levels of dispersibility and impurities within the nanomaterials. Based on the previous toxicity investigations of graphene, graphene oxide and their derivatives all exhibit in vitro toxicity. However, it showed that cells are very sensitive to size, shape, solubility, and concentration of graphene nanomaterials. GO is considered more biocompatible than graphene due to its greater solubility/dispersibility, which results in less damage and toxicity in human cell types such as skin fibroblasts and red blood cells, and bacteria. Unfortunately, there are no current or sufficient in vivo studies outlining their nanotoxicity. The results indicate that upon initial exposure of the materials, the most prominent route into the human body lies within the respiratory system. However, they are less effective in liver, kidney, and spleen. Furthermore, all cells exhibit time and dosage dependency depending upon protein adsorption and reactions governed by aggregation. As this review represents only a few studies in relation to graphene-based materials, their toxicology profile remains at the very early stages of development for a range of biomedical applications. However, before such materials reach the clinic, their toxicology profile and safety efficacies are essential steps in their evolution. Such great potential will 
offer a variety of new and powerful tools based on graphene materials for use in the areas of advanced imaging, disease diagnosis, and targeted therapies for the treatment of a range of severely debilitating diseases.

Open Access This article is distributed under the terms of the Creative Commons Attribution License which permits any use, distribution, and reproduction in any medium, provided the original author(s) and the source are credited.

\section{References}

Abou-jawde R et al (2003) An overview of targeted treatments in cancer. Clin Ther 25:2121-2137

Agarwal S et al (2010) Interfacing live cells with nanocarbon substrates. Langmuir ACS J Surf Colloids 26(4):2244-2247. http ://www.ncbi.nlm.nih.gov/pubmed/20099791. Accessed 14 Oct 2013

Abdolahad M et al (2013) Polyphenols attached graphene nanosheets for high efficiency NIR mediated photodestruction of cancer cells. Mater Sci Eng C Mater Biol Appl 33(3):1498-1505. http ://www.ncbi.nlm.nih.gov/pubmed/23827601. Accessed 20 Sept 2013.

Agemy L et al (2010) Nanoparticle-induced vascular blockade in human prostate cancer. Blood 116(15):2847-2856. http://www.pubmedcentral.nih.gov/articlerender.fcgi?artid=297 4592\& tool $=$ pmcentrez\&rendertype $=$ abstract. Accessed 16 July 2014

Akhavan $O$ et al (2013) Genotoxicity of graphene nanoribbons in human mesenchymal stem cells. Carbon 54:419-431. http://linkinghub.elsevier.com/retrieve/pii/ S0008622312009499. Accessed 20 Sept 2013

Akhavan O, Ghaderi E, Aghayee S et al (2012a) The use of a glucosereduced graphene oxide suspension for photothermal cancer therapy. J Mater Chem 22(27):13773. http://xlink.rsc.org/?DO $\mathrm{I}=\mathrm{c} 2 \mathrm{jm} 31396 \mathrm{k}$. Accessed 14 Oct 2013

Akhavan O, Ghaderi E, Rahighi R et al (2012b) Toward single-DNA electrochemical biosensing by graphene nanowalls. ACS Nano 6(4):2904-2916

Akhavan O, Choobtashani M, Ghaderi E (2012c) Protein degradation and RNA efflux of viruses photocatalyzed by graphenetungsten oxide composite under visible light irradiation. J Phys Chem 116:9653-9659

Akhavan O, Ghaderi E, Akhavan A (2012d) Size-dependent genotoxicity of graphene nanoplatelets in human stem cells. Biomaterials 33(32):8017-8025. http://www.sciencedirect.com/science/ article/pii/S0142961212008356. Accessed 28 May 2014

Akhavan O, Ghaderi E, Akhavan A (2012e) Size-dependent genotoxicity of graphene nanoplatelets in human stem cells. Biomaterials 33(32):8017-8025. http://www.ncbi.nlm.nih. gov/pubmed/22863381. Accessed 20 Sept 2013

Akhavan O, Ghaderi E (2009) Photocatalytic reduction of graphene oxide nanosheets on $\mathrm{TiO} 2$ thin film for photoinactivation of bacteria in solar light irradiation. J Phys Chem 113:20214-20220

Akhavan O, Ghaderi E (2010) Toxicity of graphene and graphene oxide nanowalls against bacteria. ACS Nano 4(10):5731-5736. http://www.ncbi.nlm.nih.gov/pubmed/20925398

Akhavan O, Ghaderi E (2012) Escherichia coli bacteria reduce graphene oxide to bactericidal graphene in a self-limiting manner. Carbon 50(5):1853-1860. http://linkinghub.elsevier.com/ retrieve/pii/S000862231100981X. Accessed 14 Oct 2013

Akhavan O, Ghaderi E, Esfandiar A (2011) Wrapping bacteria by graphene nanosheets for isolation from environment, reactivation by sonication, and inactivation by near-infrared irradiation. $\mathrm{J}$ Phys Chem B 115(19):6279-6288. http://www.ncbi.nlm.nih. gov/pubmed/21513335

Al-Nahain A et al (2013) Triggered pH/redox responsive release of doxorubicin from prepared highly stable graphene with thiol grafted pluronic. Int J Pharm 450(1-2):208-217. http://www.nc bi.nlm.nih.gov/pubmed/23624082. Accessed 20 Sept 2013

An J et al (2013) Synthesis of a biocompatible gelatin functionalized graphene nanosheets and its application for drug delivery. Mater Sci Eng C Mater Biol Appl 33(5):2827-2837. http://www.ncbi. nlm.nih.gov/pubmed/23623103. Accessed 20 Sept 2013

Bitounis D et al (2013) Prospects and challenges of graphene in biomedical applications. Adv Mater 25:2258-2268

Begum P, Fugetsu B (2013) Induction of cell death by graphene in Arabidopsis thaliana (Columbia ecotype) T87 cell suspensions. J Hazard Mater 260:1032-1041. http://www.ncbi.nlm.nih. gov/pubmed/23892171. Accessed 20 Sept 2013

Begum P, Ikhtiari R, Fugetsu B (2011) Graphene phytotoxicity in the seedling stage of cabbage, tomato, red spinach, and lettuce. Carbon 49(12):3907-3919. http://linkinghub.elsevier.com/ retrieve/pii/S0008622311003915. Accessed 20 Sept 2013

Berger C et al (2004) Ultrathin epitaxial graphite: 2D electron gas properties and a route toward graphene-based nanoelectronics. J Phys Chem 108:19912-19916

Boehm HP (1986) Editorial section nomenclature and terminology of graphite. Carbon 24(2):241-245

Boyle P, Levin B (2008) World cancer report 2008. International Agency for Reserach on Cancer

Buján J et al (2005) Muscle-derived stem cells in tissue engineering: defining cell properties suitable for construct design. Histol Histopathol 20:891-899

Calvert AH et al (1989) Carboplatin dosage: prospective evaluation of a simple formula based on renal function. J Clin Oncol 7(11):1748-1756

Carney DN et al (1983) In vitro radiation and chemotherapy sensitivity of established cell lines of human small cell lung cancer and its large cell morphological variants in vitro radiation and chemotherapy sensitivity of established cell morphological variants. Cancer Res 43:2806-2811

Chang $\mathrm{Y}$ et al (2011a) In vitro toxicity evaluation of graphene oxide on A549 cells. Toxicol Lett 200(3): 201-210. http://www.ncbi.n $1 \mathrm{~m}$. nih.gov/pubmed/21130147. Accessed 17 Sept 2013

Chang $Y$ et al (2011b) In vitro toxicity evaluation of graphene oxide on A549 cells. Toxicol Lett 200(3):201$210 . \quad$ http://www.sciencedirect.com/science/article/pii/ S0378427410017765. Accessed 28 May 2014

Chen GQ et al (1997) Use of arsenic trioxide (As2O3) in the treatment of acute promyelocytic leukemia (APL): I. As2O3 exerts dose-dependent dual effects on APL cells. Blood 89(9):33453353. http://www.ncbi.nlm.nih.gov/pubmed/9129041

Chen $\mathrm{J}$ et al (2007) Immuno gold nanocages with tailored optical properties for targeted photothermal destruction of cancer cells. Nano Lett 7:1318-1322

Chen EYT et al (2012a) Activated charcoal composite biomaterial promotes human embryonic stem cell differentiation toward neuronal lineage. J Biomed Mater Res Part A 100(8):2006$2017 . \quad$ http://www.ncbi.nlm.nih.gov/pubmed/22623371. Accessed 20 Sept 2013

Chen G-Y et al (2012b) A graphene-based platform for induced pluripotent stem cells culture and differentiation. Biomater 33(2):418-427. http://www.ncbi.nlm.nih. gov/pubmed/22014460. Accessed 20 Sept 2013

Chen M et al (2012c) Polypyrrole nanoparticles for high-performance in vivo near-infrared photothermal cancer therapy. In: Electronic supplementary materials (ESI) for chemical communications, pp 1-8 
Cheng L et al (2011) Facile preparation of multifunctional upconversion nanoprobes for multimodal imaging and dual-targeted photothermal therapy**. Multifunct Nanoparticles 50:7385-7390

Cheng L et al (2012) Organic stealth nanoparticles for highly effective in vivo near-infrared photothermal therapy of cancer. ACS Nano 6:5605-5613

Chithrani BD et al (2009) Intracellular uptake, transport, and processing of nanostructures in cancer cells. Nanomed Nanotechnol Biol Med 5(2):118-127. doi:10.1016/j.nano.2009.01.008

Compton OC, Nguyen ST (2010) Graphene oxide, highly reduced graphene oxide, and graphene: versatile building blocks for carbon-based materials. Small (Weinheim an der Bergstrasse, Germany) 6(6):711-723. http://www.ncbi.nlm.nih. gov/pubmed/20225186. Accessed 19 Sept 2013

Cui D et al (2005) Effect of single wall carbon nanotubes on human HEK293 cells. Toxicol Lett 155(1):73-85. http://www.ncbi.nlm .nih.gov/pubmed/15585362. Accessed 4 June 2014

Daadi MM et al (2012) Dopaminergic neurons from midbrain-specified human embryonic stem cell-derived neural stem cells engrafted in a monkey model of Parkinson' s disease. PLoS ONE 7:1-11

Danova-alt $R$ et al (2012) Very small embryonic-like stem cells purified from umbilical cord blood lack stem cell characteristics. PLoS ONE 7:1-11

Da Ros T, Spalluto G, Prato M (2001) Biological applications of fullerene derivatives: a brief overview. Croatica Chemica Acta 74(4):743-755

Deaths PC (2011) Cancer statistics, 2011 the impact of eliminating socioeconomic and racial disparities on premature cancer deaths. Cancer J Clin 61:212-236

Deepachitra R et al (2013) Osteo mineralization of fibrin-decorated graphene oxide. Carbon 56:64-76. http://linkinghub. elsevier.com/retrieve/pii/S0008622312010378. Accessed 20 Sept 2013

Depan D et al (2011) Structure-process-property relationship of the polar graphene oxide-mediated cellular response and stimulated growth of osteoblasts on hybrid chitosan network structure nanocomposite scaffolds. Acta Biomater 7(9):3432-3445. http ://www.ncbi.nlm.nih.gov/pubmed/21664303. Accessed 20 September 2013

Dong W et al (2011) Facile synthesis of monodisperse superparamagnetic Fe3 O4 core@ hybrid @ Au shell nanocomposite for bimodal imaging and photothermal therapy. Adv Mater 23:5392-5397

Donnelly EM, Lamanna J, Boulis NM (2012) Stem cell therapy for the spinal cord. Stem Cell Res Therapy 3:1-9

Dreyer DR, Ruoff RS, Bielawski CW (2010) From conception to realization: an historial account of graphene and some perspectives for its future. Angew Chem (International ed. in English) 49(49):9336-9344. http://www.ncbi.nlm.nih. gov/pubmed/21110353. Accessed 26 Feb 2014

Duch MC et al (2011) Minimizing oxidation and stable nanoscale dispersion improves the biocompatibility of graphene in the lung. Nano Lett 11:5201-5207

Fako VE, Furgeson DY (2009) Zebrafish as a correlative and predictive model for assessing biomaterial nanotoxicity. Adv Drug Deliv Rev 61(6):478-486. http://www.ncbi.nlm.nih. gov/pubmed/19389433. Accessed 16 July 2014

Feng L et al (2011) A graphene functionalized electrochemical aptasensor for selective label-free detection of cancer cells. Biomaterials 32(11):2930-2937. http://www.ncbi.nlm.nih. gov/pubmed/21256585. Accessed 20 Sept 2013

Feng L, Liu Z (2011) Graphene in biomedicine: opportunities and challenges special report. Future Med 6:317-324

Gajewicz A et al (2012) Advancing risk assessment of engineered nanomaterials: application of computational approaches. Adv
Drug Deliv Rev 64(15):1663-1693. http://www.ncbi.nlm.nih. gov/pubmed/22664229. Accessed 23 May 2014

Ganat YM et al (2012) Identification of embryonic stem cell-derived midbrain dopaminergic neurons for engraftment. J Clin Investig 122:2928-2939

Geiger S et al (2010) Anticancer therapy induced cardiotoxicity: review of the literature. Anticancer Therapy Induced Cardiotoxicity 21:578-590

Geim AK, Novoselov KS (2007) The rise of graphene. Nat Mater 6(3):183-191. http://www.ncbi.nlm.nih.gov/pubmed/17330084

Gollavelli G, Ling Y-C (2012) Multi-functional graphene as an in vitro and in vivo imaging probe. Biomaterials 33(8):2532-2545. http://www.ncbi.nlm.nih.gov/pubmed/22206596. Accessed 20 Sept 2013

Graphene S et al (2010) Organic light-emitting diodes on solution-processed graphene transparent electrodes. ACS Nano 4(1):43-48

Grayson AMYCR et al (2003) Multi-pulse drug delivery from a resorbable polymeric microchip device. Nat Mater 2:767-772

Guo M et al (2013) Nitrogen ion implanted graphene as thrombo-protective safer and cytoprotective alternative for biomedical applications. Carbon 61:321-328. http://linkinghub.elsevier.com/ retrieve/pii/S0008622313004247. Accessed 20 Sept 2013

Gurunathan S, Han JW, Dayem AA et al (2013a) Antibacterial activity of dithiothreitol reduced graphene oxide. J Ind Eng Chem 19(4):1280-1288. http://linkinghub.elsevier.com/retrieve/pii/ S1226086X12004492. Accessed 20 Sept 2013

Gurunathan S, Han JW, Eppakayala V et al (2013b). Biocompatibility of microbially reduced graphene oxide in primary mouse embryonic fibroblast cells. Colloids Surf B Biointerfaces 105:58-66. http://www.ncbi.nlm.nih.gov/pubmed/23352948. Accessed 20 Sept 2013

Hauck BTS et al (2008) Enhancing the toxicity of cancer chemotherapeutics with gold nanorod hyperthermia **. Adv Mater 20:3832-3838

Heo C et al (2011) The control of neural cell-to-cell interactions through non-contact electrical field stimulation using graphene electrodes. Biomaterials 32(1):19-27. http://www.ncbi.nlm.nih. gov/pubmed/20880583. Accessed 24 Sept 2013

Hoare $\mathrm{T}$ et al (2009) A magnetically triggered composite membrane for on-demand drug delivery. Nano Lett 9:13-18

Hong $\mathrm{H}$ et al (2012) In vivo targeting and positron emission tomography imaging of tumor vasculature with (66)Ga-labeled nano-graphene. Biomaterials 33(16):4147-4156. http://www.pubmedcentral.nih. gov/articlerender.fcgi?artid $=3313015 \&$ tool $=$ pmcentrez\&rendert ype $=$ abstract. Accessed 20 Sept 2013

Horváth L et al (2013) Evaluation of the toxicity of graphene derivatives on cells of the lung luminal surface. Carbon 64:45-60. http://linkinghub.elsevier.com/retrieve/pii/ S000862231300626X. Accessed 20 Sept 2013

$\mathrm{Hu}$ W et al (2010) Graphene-based antibacterial paper. ACS Nano 4(7):4317-23. http://www.ncbi.nlm.nih.gov/pubmed/20593851

$\mathrm{Hu} \mathrm{W}$ et al (2011) Protein corona-mediated mitigation of cytotoxicity of graphene oxide. ACS Nano 5(5):3693-3700. http://www.ncbi .nlm.nih.gov/pubmed/21500856

$\mathrm{Hu} \mathrm{Z}$ et al (2012) Visible light driven photodynamic anticancer activity of graphene oxide/TiO2 hybrid. Carbon 50(3):994-1004. http://linkinghub.elsevier.com/retrieve/pii/S0008622311008219. Accessed 20 Sept 2013

Hu X, Zhou Q (2014) Novel hydrated graphene ribbon unexpectedly promotes aged seed germination and root differentiation. Sci Rep 4:3782. http://www.pubmedcentral.nih.gov/articlerender. fcgi $?$ artid $=3896910 \&$ tool $=$ pmcentrez $\&$ rendertype $=$ abstract . Accessed 18 June 2014

Huang X et al (2006) Cancer cell imaging and photothermal therapy in the near-infrared region by using gold nanorods. J Am Chem Soc 128:2115-2120 
Huang P et al (2012) Light-triggered theranostics based on photosensitizer- conjugated carbon dots for simultaneous enhancedfluorescence imaging and photodynamic therapy. Adv Mater 24:5104-5110

Hummers WS, Offeman RE (1958) Preparation of graphitic oxide. J Am Chem Soc 80:1339

Jaracz S et al (2005) Recent advances in tumor-targeting anticancer drug conjugates. Bioorganic Med Chem 13:5043-5054

Jemal A, Bray F, Ferlay J (2011) Global cancer statistics. CA Cancer J Clin 61:69-90

Jing Y (2001) Combined effect of all-trans retinoic acid and arsenic trioxide in acute promyelocytic leukemia cells in vitro and in vivo. Blood 97(1): 264-269. http://www.bloodjournal.org/cgi/ doi/10.1182/blood.V97.1.264. Accessed 15 Oct 2013

Jokerst JV, Gambhir SS (2011) Molecular imaging with theranostic nanoparticles. Acc Chem Res 44:1050-1060

Kanakia S et al (2014) Dose ranging, expanded acute toxicity and safety pharmacology studies for intravenously administered functionalized graphene nanoparticle formulations. Biomaterials 35(25):7022-7031. http://www.ncbi.nlm.nih. gov/pubmed/24854092. Accessed 7 July 2014

Kayat J et al (2011) Pulmonary toxicity of carbon nanotubes: a systematic report. Nanomed Nanotechnol Biol Med 7(1):40-49. http://www.ncbi.nlm.nih.gov/pubmed/20620235. Accessed 31 May 2014

Kim Y-K, Kim M-H, Min D-H (2011) Biocompatible reduced graphene oxide prepared by using dextran as a multifunctional reducing agent. Chem Commun (Cambridge, England) 47(11):3195-3197. http://www.ncbi.nlm.nih. gov/pubmed/21286628. Accessed 14 Oct 2013

Kim T-H, Lee K-B, Choi J-W (2013) 3D graphene oxide-encapsulated gold nanoparticles to detect neural stem cell differentiation. Biomaterials 34(34):8660-8670. http://www.ncbi.nlm.nih. gov/pubmed/23937915. Accessed 20 Sept 2013

Kintzel PE, Dorrt RT (1995) Anticancer drug renal toxicity and elimination: dosing guidelines fro altered renal function. Cancer Treat Rev 21:33-64

Kouranos V et al (2011) Chemotherapy-induced neutropenia in lung cancer patients: the role of antibiotic prophylaxis. Cancer Lett 313(1):9-14. http://www.ncbi.nlm.nih.gov/pubmed/21955615. Accessed 15 Oct 2013

Ku SH, Park CB (2013) Myoblast differentiation on graphene oxide. Biomaterials 34(8):2017-2023. http://www.ncbi.nlm.nih. gov/pubmed/23261212. Accessed 20 Sept 2013

Lacerda L et al (2006) Carbon nanotubes as nanomedicines: from toxicology to pharmacology. Adv Drug Deliv Rev 58(14):1460$1470 . \quad$ http://www.ncbi.nlm.nih.gov/pubmed/17113677. Accessed 22 Sept 2013

Lam $C$ et al (2006) A review of carbon nanotube toxicity and assessment of potential occupational and environmental health risks. Crit Rev Toxicol 36(3):189-217. doi:10.1080/10408440600570233. Accessed 17 Sept 2013

Lee BS, Park H, Yoo K (2010) Synergistic cancer therapeutic effects of locally delivered drug and heat using multifunctional nanoparticles. Adv Mater 22:4049-4053

Lee C et al (2008) Measurement of the elastic properties and intrinsic strength of monolayer graphene. Science (New York, NY) 321(5887):385-388. http://www.ncbi.nlm.nih. gov/pubmed/18635798. Accessed 17 Sept 2013

Lee HJ et al (2011) Amine-modified single-walled carbon nanotubes protect neurons from injury in a rat stroke model. Nat Nanotechnol 6(2):121-5. http://www.ncbi.nlm.nih. gov/pubmed/21278749. Accessed 28 Sept 2013

Li D et al (2008) Processable aqueous dispersions of graphene nanosheets. Nat Nanotechnol 3(2):101-105. http://www.ncbi.n lm.nih.gov/pubmed/18654470. Accessed 24 Sept 2013
Li N et al (2011) The promotion of neurite sprouting and outgrowth of mouse hippocampal cells in culture by graphene substrates. Biomaterials 32(35):9374-9382. http://www.ncbi.nlm.nih. gov/pubmed/21903256. Accessed 20 Sept 2013

$\mathrm{Li} \mathrm{X}$ et al (2009) Evolution of graphene growth on $\mathrm{Ni}$ and $\mathrm{Cu}$ by carbon isotope labeling. Nano Lett 9(12):4268-4272. http://pubs.acs.org/ doi/abs/10.1021/n1902515k. Accessed 17 Sept 2013

Li X et al (2012a) Engineering neural stem cell fates with hydrogel design for central nervous system regeneration. Prog Polym Sci 37(8):1105-1129. http://linkinghub.elsevier.com/retrieve/pii/ S0079670012000202. Accessed 21 Oct 2013

Li Y et al (2012b) The triggering of apoptosis in macrophages by pristine graphene through the MAPK and TGF-beta signaling pathways. Biomaterials 33(2):402-411. http://www.ncbi.nlm.nih. gov/pubmed/22019121. Accessed 20 Sept 2013

Liang X (2011) Theranostic nanoparticles engineered for clinic and pharmaceutics. Acc Chem Res 44:1114-1122

Liao K-H et al (2011) Cytotoxicity of graphene oxide and graphene in human erythrocytes and skin fibroblasts. ACS Appl Mater Interfaces 3(7):2607-2615. http://www.ncbi.nlm.nih. gov/pubmed/21650218

Liu X et al (2011) Biomaterials Optimization of surface chemistry on single-walled carbon nanotubes for in vivo photothermal ablation of tumors $\mathrm{OH} \mathrm{O} \mathrm{OH} \mathrm{O} \mathrm{OH} \mathrm{O} \mathrm{OH} \mathrm{O} \mathrm{OH} \mathrm{O.} \mathrm{Biomaterials}$ 32(1):144-151. doi:10.1016/j.biomaterials.2010.08.096

Liu $\mathrm{Z}$ et al (2008) PEGylated nanographene oxide for delivery of water-insoluble cancer drugs. J Am Chem Soc 130(33):1087610877. http://www.pubmedcentral.nih.gov/articlerender.fcgi?art $\mathrm{id}=2597374 \&$ tool $=$ pmcentrez\&rendertype $=$ abstract

Liu Z et al (2009) Carbon nanotubes in biology and medicine: in vitro and in vivo detection, imaging and drug delivery. Nano Res 2(2):85-120. www.pubmedcentral.nih.gov/articlerender.fcgi?art $\mathrm{id}=2824900 \&$ tool $=$ pmcentrez $\&$ rendertype $=$ abstract . Accessed 23 Sept 2013

Lu J et al (2008) Light-activated nanoimpeller-controlled drug release in cancer cells. Small (Weinheim an der Bergstrasse, Germany) 4(4):421-426. http://www.pubmedcentral.nih.gov/articlerende r.fcgi $?$ artid $=2712492 \&$ tool $=$ pmcentrez $\&$ rendertype $=$ abstract . Accessed 19 Oct 2013

Lu X, Huang H et al (1999a) Patterning of highly oriented pyrolytic graphite by oxygen plasma etching. Appl Phys Lett 75(2):193. doi: 10.1063/1.124316. http://link.aip.org/link/APPLAB/v75/i2/ p193/s1\&Agg=doi

Lu X, Yu M, et al (1999b) Tailoring graphite with the goal of achieving single sheets. Nanotechnology 10(3):269-272. http:// stacks.iop.org/0957-4484/10/i=3/a=308?key $=$ crossref. $22752 \mathrm{~d}$ ba6bf4b8ec945307fba882d872

Ma J et al (2011) Preparation, characterization and antibacterial properties of silver-modified graphene oxide. J Mater Chem 21(10):3350. http://xlink.rsc.org/?DOI=c0jm02806a. Accessed 14 Oct 2013

Ma D et al (2012) In situ gelation and sustained release of an antitumor drug by graphene oxide nanosheets. Carbon 50(8):3001-3007. http://linkinghub.elsevier.com/retrieve/pii/ S0008622312002205. Accessed 20 Sept 2013

Manuscript A (2009) Co-delivery of siRNA and an anticancer drug for treatment of multidrug-resistant cancer. Nanomedicine 3:761-776

Manuscript A, Factors R (2008) Non-small cell lung cancer: epidemiology and survivorship. Mayo Clin Proc 83:584-594

Mao H et al (2013a) Hard corona composition and cellular toxicities of the graphene sheets. Colloids Surf B Biointerfaces 109:212218. http://www.ncbi.nlm.nih.gov/pubmed/23643918. Accessed 20 Sept 2013

Mao HY et al (2013b) Graphene: promises, facts, opportunities, and challenges in nanomedicine. Chem Rev 113(5):3407-3424. http ://www.ncbi.nlm.nih.gov/pubmed/23452512 
Markovic ZM et al (2011) In vitro comparison of the photothermal anticancer activity of graphene nanoparticles and carbon nanotubes. Biomaterials 32(4):1121-1129. http://www.ncbi.nlm.nih. gov/pubmed/21071083. Accessed 20 Sept 2013

Melancon MP, Zhou MIN, Li C (2011) Cancer theranostics with nearinfrared light-activatable multimodal nanoparticles. Acc Chem Res 44:947-956

Miao W et al (2013) Safety and tumor tissue accumulation of pegylated graphene oxide nanosheets for co-delivery of anticancer drug and photosensitizer. Biomaterials 34(13):3402-3410. http://www.ncbi.nlm.nih.gov/pubmed/23380350. Accessed 20 Sept 2013

Mohanty N, Berry V (2008) Graphene-based single-bacterium resolution biodevice and DNA transistor: interfacing graphene derivatives with nanoscale and microscale biocomponents. Nano Lett 8(12):4469-4476

Moon HK, Lee SH, Choi HC (2009) In vivo near-infrared mediated tumor destruction by photothermal effect of carbon nanotubes. ACS Nano 3:3707-3713

Mullick Chowdhury S et al (2013) Cell specific cytotoxicity and uptake of graphene nanoribbons. Biomaterials 34(1):283-293. http://www.ncbi.nlm.nih.gov/pubmed/23072942. Accessed 20 Sept 2013

Mura S, Couvreur P (2012) Nanotheranostics for personalized medicine $\star$. Adv Drug Deliv Rev 64(13):1394-1416. doi:10.1016/j.addr.2012.06.006

Nakamura E, Isobe H (2003) Functionalized fullerenes in water. The first 10 years of their chemistry, biology, and nanoscience. Accounts Chem Res 36(11):807-815. http://www.ncbi.nlm.nih. gov/pubmed/14622027

Narang AS, Varia S (2011) Role of tumor vascular architecture in drug delivery. Adv Drug Deliv Rev 63(8):640-658. doi:10.1016/j.addr.2011.04.002

Nel A (2005) Air pollution-related illness: effects of particles. Science 308:804-806

Nel A et al (2006) Toxic potential of materials at the nanolevel. Science 311:622-627

Novoselov KS et al (2012) A roadmap for graphene. Nature 490(7419):192-200. http://www.ncbi.nlm.nih. gov/pubmed/23060189. Accessed 20 Jan 2014

Novoselov KS et al (2004) Electric field effect in atomically thin carbon films. Science (New York, NY) 306(5696):666-669. http:// www.ncbi.nlm.nih.gov/pubmed/15499015

Oberdörster G, Oberdörster E, Oberdörster J (2005) Nanotoxicology : an emerging discipline evolving from studies of ultrafine particles supplemental web sections. Environ Health Perspect 113(7):823-839

Panessa-Warren BJ, Wong SS, Misewich JA (2006) Biological cellular response to carbon nanoparticle toxicity. J Phys 18:2185-2201

Panessa-Warren BJ et al (2008) Human epithelial cell processing of carbon and gold nanoparticles. Int J Nanotechnol 5:55-91

Park S et al (2010) Biocompatible, robust free-standing paper composed of a TWEEN/graphene composite. Adv Mat (Deerfield Beach, Fla.), 22(15):1736-1740. http://www.ncbi.nlm.nih. gov/pubmed/20496406. Accessed 8 Oct 2013

Piao S et al (2012) Therapeutic effect of adipose-derived stem cells and BDNF-immobilized PLGA membrane in a rat model of. Int Soc Sex Med 9:1968-1979

Pinto AM et al (2013) Biocompatibility of poly(lactic acid) with incorporated graphene-based materials. Colloids Surf B Biointerfaces 104:229-238. http://www.ncbi.nlm.nih. gov/pubmed/23333912. Accessed 20 Sept 2013

Qiao Y, An J, Ma L (2013) Single cell array based assay for in vitro genotoxicity study of nanomaterials. Anal Chem 85(8):41074112. http://www.ncbi.nlm.nih.gov/pubmed/23521522
Qin XC et al (2013) Folic acid-conjugated graphene oxide for cancer targeted chemo-photothermal therapy. J Photochem Photobiol B Biol 120:156-162. http://www.ncbi.nlm.nih. gov/pubmed/23357205. Accessed 20 Sept 2013

Qiu Y et al (2011) Electrochemical detection of DNA damage induced by acrylamide and its metabolite at the grapheneionic liquid-Nafion modified pyrolytic graphite electrode. J Hazard Mater 190(1-3):480-485. http://www.ncbi.nlm.nih. gov/pubmed/21497017. Accessed 20 Sept 2013

Ragot J, Ag BM, Stewardship GP (2010) Toxicity of carbon nanotubes. In: Joint CASG-Nano and ENPRAV workshop on early harvest of research results on nanosafety. Ispra, Italy, 14-15 April 2010

Rao CNR et al (2009) Graphene: the new two-dimensional nanomaterial. Angew Chem (International ed. in English) 48(42):775277. http://www.ncbi.nlm.nih.gov/pubmed/19784976. Accessed 21 Sept 2013

Rong P et al (2014) Photosensitizer loaded nano-graphene for multimodality imaging guided tumor photodynamic therapy. Theranostics 4(3):229-239. http://www.pubmedcentral.nih.gov/articl erender.fcgi $?$ artid $=3915087 \&$ tool $=$ pmcentrez\&rendertype $=a b$ stract. Accessed 23 Feb 2014

Sahu A et al (2013) Graphene oxide mediated delivery of methylene blue for combined photodynamic and photothermal therapy. Biomaterials 34(26):6239-6248. http://www.ncbi.nlm.nih. gov/pubmed/23706688. Accessed 20 Sept 2013

Santini JT Jr, Cima MJ, Langer R (1999) A controlled-release microchip. Nature 397:335-338

Sasidharan A et al (2011) Differential nano-bio interactions and toxicity effects of pristine versus functionalized graphene. Nanoscale 3(6):2461-2464. http://www.ncbi.nlm.nih. gov/pubmed/21562671. Accessed 4 Oct 2013

Sasidharan A et al (2012) Hemocompatibility and macrophage response of pristine and functionalized graphene. Small (Weinheim an der Bergstrasse, Germany) 8(8):1251-1263. http://ww w.ncbi.nlm.nih.gov/pubmed/22334378. Accessed 16 July 2014

Schinwald, A. et al (2012). Graphene-based nanoplatelets: a new risk to the respiratory system as a consequence of their unusual aerodynamic properties. ACS nano, 6(1), pp 736-46. http://www.n cbi.nlm.nih.gov/pubmed/22195731

Seabra AB et al (2014) Nanotoxicity of graphene and graphene oxide. Chem Res Toxicol 27(2):159-168. http://www.ncbi.nlm.nih. gov/pubmed/24422439

Sebastian D (2012) Material safety data sheet trade name: grapheneareduced graphene oxide

Service RF (2003) Nanomaterials show signs of toxicity. Science 300:243

Shao Y et al (2010) Graphene based electrochemical sensors and biosensors: a review. Electroanalysis 22(10):1027-1036. doi:10.1002/elan.200900571. Accessed 18 Sept 2013

Sheng Z et al (2013) Protein-assisted fabrication of nano-reduced graphene oxide for combined in vivo photoacoustic imaging and photothermal therapy. Biomaterials 34(21):5236-5243. http:/ /www.ncbi.nlm.nih.gov/pubmed/23602365. Accessed 20 Sept 2013

Sherlock SP et al (2012) Photothermally enhanced drug delivery by ultra-small multifunctional $\mathrm{FeCo} /$ graphene-shell nanocrystals. ACS Nano 5:1505-1512

Shi $S$ et al (2013a) Biomaterials tumor vasculature targeting and imaging in living mice with reduced graphene oxide. Biomaterials 34(12):3002-3009. doi:10.1016/j.biomaterials.2013.01.047

Shi X et al (2013b) Graphene-based magnetic plasmonic nanocomposite for dual bioimaging and photothermal therapy. Biomaterials 34(20):4786-4793. http://www.ncbi.nlm.nih. gov/pubmed/23557860. Accessed 20 Sept 2013 
Singh SK et al (2011) Thrombus inducing property of atomically thin graphene oxide sheets. ACS Nano 5(6):4987-4996. http://www. ncbi.nlm.nih.gov/pubmed/21574593

Singh SK et al (2012) Amine-modified graphene: thrombo-protective safer alternative to graphene oxide for biomedical applications. ACS Nano 6(3):2731-2740. http://www.ncbi.nlm.nih. gov/pubmed/24660818

Stankovich S et al (2006) Graphene-based composite materials. Nature 442(7100):282-286. http://www.ncbi.nlm.nih. gov/pubmed/16855586. Accessed 6 Aug 2013

Steindler DA, Okun MS (2012) Stem cell pathologies and neurological disease. Mod Pathol 25:157-162

Sun $X$ et al (2008) Nano-graphene oxide for cellular imaging and drug delivery. Nano Res 1(3):203-212. http://www.pubmedcentral.nih.gov/articlerender.fcgi?artid=2 $834318 \&$ tool $=$ pmcentrez\&rendertype $=$ abstract. Accessed 24 Sept 2013

Tang Y, Mcgoron AJ (2009) Combined effects of laser-ICG photothermotherapy and doxorubicin chemotherapy on ovarian cancer cells. J Photochem Photobiol B Biol 97(3):138-144. doi:10.1016/j.jphotobiol.2009.09.001

Tang Y et al (2010) Simultaneous delivery of chemotherapeutic and thermal-optical agents to cancer cells by a polymeric (PLGA) nanocarrier: an in vitro study. Pharm Res 27:2242-2253

Thomas CR et al (2010) Noninvasive remote-controlled release of drug molecules in vitro using magnetic actuation of mechanized nanoparticles. Am Chem Soc 123:10623-10625

Tian B et al (2011) Photothermally enhanced photodynamic therapy delivered by nano-graphene oxide. ACS Nano 9:7000-7009

Toxicology DB (1990) Toxicological versus ecotoxicological testing. In: Bourdeau P (ed) Short-term toxicity tests for non-genotoxic effects. Wiley, New York

Tripathi SK et al (2013) Functionalized graphene oxide mediated nucleic acid delivery. Carbon 51:224-235. http://linkinghub. elsevier.com/retrieve/pii/S0008622312006999. Accessed 20 Sept 2013

Umezawa $\mathrm{H}$ et al (1966) New antibiotics, bleomycin A and B. J Antibiot 19(5):200-209

Van Bommel AJ, Crombeen JE, Van Tooren A (1975) Leed and Auger electron observations of the SiC (0001) surface. Surf Sci 48:463-472

Vallabani NVS et al (2011) Toxicity of graphene in normal human lung cells (BEAS-2B). J Biomed Nanotechnol 7(1):106-107. http://www.ncbi.nlm.nih.gov/pubmed/21485826. Accessed 16 July 2014

Voortman J, Giaccone G (2006) Severe reversible cardiac failure after bortezomib treatment combined with chemotherapy in a nonsmall cell lung cancer patient: a case report. BMC Cancer 6:4-7

Wan B et al (2013) Single-walled carbon nanotubes and graphene oxides induce autophagosome accumulation and lysosome impairment in primarily cultured murine peritoneal macrophages. Toxicol Lett 221(2):118-127. http://www.ncbi.nlm. nih.gov/pubmed/23769962. Accessed 20 Sept 2013

Wang K et al (2010) Biocompatibility of graphene oxide. Nanoscale Res Lett pp 1-8. http://www.nanoscalereslett.com/content/6/1/8. Accessed 27 Sept 2013

Wang C et al (2011) Gold nanoclusters and graphene nanocomposites for drug delivery and imaging of cancer cells $* *$. Cell Interact 50:11644-11648

Wang W et al (2012) Preparation of reduced graphene oxide/gelatin composite films with reinforced mechanical strength. Mater Res Bull 47(9):2245-2251. http://linkinghub.elsevier.com/ retrieve/pii/S0025540812004370. Accessed 20 Sept 2013

Wang X et al (2012) Noble metal coated single-walled carbon nanotubes for applications in surface enhanced raman scattering imaging and photothermal therapy. J Am Soc 134:7414-7422
Wang A et al (2013a) Role of surface charge and oxidative stress in cytotoxicity and genotoxicity of graphene oxide towards human lung fibroblast cells. J Appl Toxicol JAT 33(10):1156-1164. http://www.ncbi.nlm.nih.gov/pubmed/23775274. Accessed 20 Sept 2013

Wang C et al (2013b) A chitosan-modified graphene nanogel for noninvasive controlled drug release. Nanomed Nanotechnol Biology Medicine. pp 1-9. http://www.ncbi.nlm.nih. gov/pubmed/23352802. Accessed 17 Sept 2013

Wei W et al (2013) Colorimetric detection of DNA damage by using hemin-graphene nanocomposites. Spectrochim Acta Part A Mol Biomol Spectrosc 106:163-169. http://www.ncbi.nlm.nih. gov/pubmed/23376271. Accessed 6 July 2014

Wintterlin J, Bocquet M-L (2009) Graphene on metal surfaces. Surf Sci 603(10-12):1841-1852. http://linkinghub.elsevier.com/ retrieve/pii/S003960280900079X. Accessed 25 Sept 2013

Wojtoniszak M et al (2012) Synthesis, dispersion, and cytocompatibility of graphene oxide and reduced graphene oxide. Colloids Surf B Biointerfaces 89:79-85. http://www.ncbi.nlm.nih. gov/pubmed/21962852. Accessed 20 September 2013

Wood B (2013) The to and fro of tumor spread. New Views Res 493:8-9

Worth AP (2010) The role of QSAR methodology in the regulatory assessment of chemicals. Recent Adv QSAR Stud Chall Adv Comput Chem Phys 8:367-382

Wu X et al (2010) High-photoluminescence-yield gold nanocubes: for cell imaging and photothermal therapy. ACS Nano 4:113-120

Wu Q et al (2014) microRNAs control of in vivo toxicity from graphene oxide in Caenorhabditis elegans. Nanomed Nanotechnol Biol Med. pp 1-10. http://www.ncbi.nlm.nih. gov/pubmed/24780312. Accessed 7 July 2014

Xie Z et al (2012) Floor plate-delivered dopamine neurons from hESCS efficiently engraft in animal models of PD. Nature 480:547-551

$\mathrm{Xu}$ Y et al (2012) Promising new potential for mesenchymal stem cells derived from human umbilical cord Wharton's jelly : sweat gland cell-like differentiative capacity. J Tissue Eng Regen Med 6:645-654

Yan L et al (2013) The use of polyethylenimine-modified graphene oxide as a nanocarrier for transferring hydrophobic nanocrystals into water to produce water-dispersible hybrids for use in drug delivery. Carbon 57:120-129. http://linkinghub.elsevier.com/ retrieve/pii/S0008622313000638. Accessed 20 Sept 2013

Yang K et al (2010) Graphene in mice: ultrahigh in vivo tumor uptake and efficient photothermal therapy. Nano Lett 10(9):3318-3323. http://www.ncbi.nlm.nih.gov/pubmed/20684528. Accessed 26 Sept 2013

Yang $\mathrm{K}$ et al (2011a) In vivo pharmacokinetics, long-term biodistribution, and toxicology of pegylated graphene in mice. ACS Nano $5(1): 516-522$

Yang X et al (2011b) Multi-functionalized graphene oxide based anticancer drug-carrier with dual-targeting function and $\mathrm{pH}$-sensitivity. J Mater Chem 21:3448-3454

Yang K, Hu L et al (2012a) Multimodal imaging guided photothermal therapy using functionalized graphene nanosheets anchored with magnetic nanoparticles. Adv Mater 24:1868-1872

Yang K, Wan J, et al (2012b) The influence of surface chemistry and size of nanoscale graphene oxide on photothermal therapy of cancer using ultra-low laser power. Biomaterials 33(7):22062214 . http://www.ncbi.nlm.nih.gov/pubmed/22169821. Accessed 24 Sept 2013

Yang K, Xu H et al (2012c) In vitro and in vivo near-infrared photothermal therapy of cancer using polypyrrole organic nanoparticles. Adv Mater 24:5586-5592

Yang $\mathrm{K}$ et al (2013a) In vivo biodistribution and toxicology of functionalized nano-graphene oxide in mice after oral and 
intraperitoneal administration. Biomaterials 34(11):2787-2795. http://www.ncbi.nlm.nih.gov/pubmed/23340196. Accessed 16 July 2014

Yang M et al (2013b) A high poly(ethylene glycol) density on graphene nanomaterials reduces the detachment of lipid-poly(ethylene glycol) and macrophage uptake. Acta Biomater 9(1):4744-4753. http://www.ncbi.nlm.nih. gov/pubmed/22995407. Accessed 20 Sept 2013

Yavuz MS et al (2009) Gold nanocages covered by smart polymers for controlled release with near-infrared light. Nat Mater 8(12):935-939. doi:10.1038/nmat2564

Yoon OJ, Kim CH et al (2013a) Toxicity analysis of graphene nanoflakes by cell-based electrochemical sensing using an electrode modified with nanocomposite of graphene and Nafion. Sensors Actuators B Chem 188:454-461. http://linkinghub.elsevier.com/ retrieve/pii/S0925400513008368. Accessed 20 Sept 2013

Yoon OJ, Kim I et al (2013b) Toxicity of graphene nanoflakes evaluated by cell-based electrochemical impedance biosensing. J Biomed Mater Res Part A. pp 1-7. http://www.ncbi.nlm.nih. gov/pubmed/23894129. Accessed 20 Sept 2013

Yuan J, Gao H, Ching CB (2011) Comparative protein profile of human hepatoma HepG2 cells treated with graphene and singlewalled carbon nanotubes: an iTRAQ-coupled 2D LC-MS/MS proteome analysis. Toxicol Lett 207(3):213-221. http://www.nc bi.nlm.nih.gov/pubmed/21963432. Accessed 20 Sept 2013

Zha Z et al (2013) Uniform polypyrrole nanoparticles with high photothermal conversion efficiency for photothermal ablation of cancer cells. Adv Mater 25:777-782

Zhang L et al (2010a) Functional graphene oxide as a nanocarrier for controlled loading and targeted delivery of mixed anticancer drugs. Drug Deliv 6(4):537-544. http://www.ncbi.nlm.nih. gov/pubmed/20033930. Accessed 3 Oct 2013
Zhang Y et al (2010b) Cytotoxicity effects of graphene and singlewall carbon nanotubes in neural phaeochromocytoma-derived PC12 cells. ACS Nano 4(6):3181-3186

Zhang $W$ et al (2011a) Synergistic effect of chemo-photothermal therapy using PEGylated graphene oxide. Biomaterials 32(33):8555-8561. http://www.ncbi.nlm.nih. gov/pubmed/21839507. Accessed 20 Sept 2013

Zhang X et al (2011b) Distribution and biocompatibility studies of graphene oxide in mice after intravenous administration. Carbon 49(3):986-995. http://linkinghub.elsevier.com/retrieve/pii/ S0008622310007967. Accessed 20 Sept 2013

Zhang $\mathrm{M}$ et al (2013) The effect of graphene oxide on conformation change, aggregation and cytotoxicity of HIV-1 regulatory protein (Vpr). Biomaterials 34(4):1383-1390. http://www.ncbi.nlm .nih.gov/pubmed/23153418. Accessed 20 Sept 2013

Zhao X, Liu R (2012) Recent progress and perspectives on the toxicity of carbon nanotubes at organism, organ, cell, and biomacromolecule levels. Environ Int 40:244-255

Zhou J et al (2012a) Detection of DNA damage by using hairpin molecular beacon probes and graphene oxide. Talanta 99:625630. http://www.ncbi.nlm.nih.gov/pubmed/22967603. Accessed 20 Sept 2013

Zhou L et al (2012b) High-efficiency loading of hypocrellin $\mathrm{B}$ on graphene oxide for photodynamic therapy. Carbon 50(15):5594-5604. http://linkinghub.elsevier.com/retrieve/pii/ S0008622312006653. Accessed 20 Sept 2013

Zhu Y et al (2010) Graphene and graphene oxide: synthesis, properties, and applications. Adv Mater (Deerfield Beach, Fla.) 22(35):3906-3924. http://www.ncbi.nlm.nih. gov/pubmed/20706983. Accessed 7 Aug 2013 